الأمر عند الأصوليين في ضوء التداولية

$$
\begin{aligned}
& \text { دكتور / محمد مسعود علي حسن عيسى } \\
& \text { دكتوراه في العلوم اللغوية - كلية الآداب }
\end{aligned}
$$

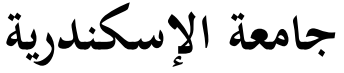


بسم الله والحمد لله والصلاة والسلام على رسول الله . وبعد فقد دفعني إلى الكتابة

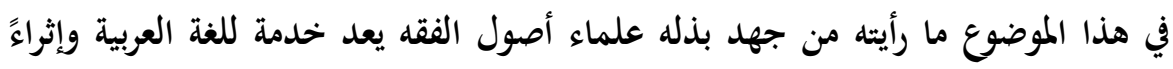
لها، ولست أزعم أني أول من كتب عن جهود الأصوليين في خدمة اللغة العربية ، فلقد بلد العداء

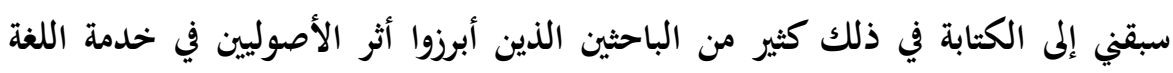

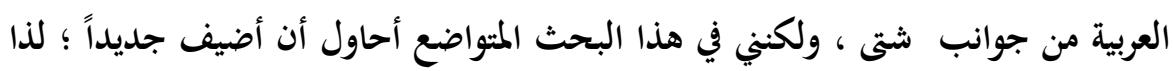

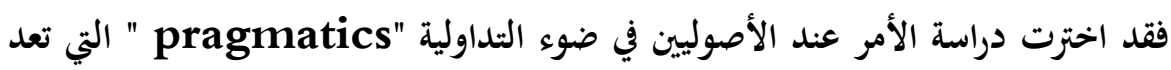
أحد الإتجاهات اللغوية الحديثة . فما وجدته في كتب الأصوليين من دراسة للأمر وصيغه،

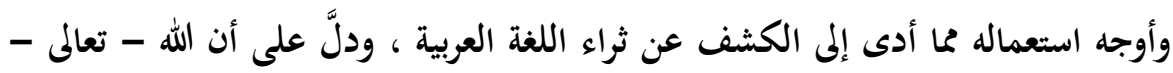
امتنَّ على هؤلاء العلماء بنعمة الذكاء والعبقرية ، فقد وفقهم الله لهذه الدراسة المستفيضة الكماء

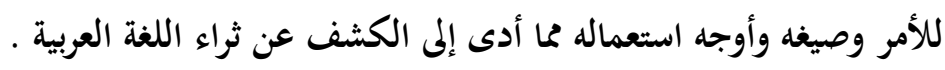

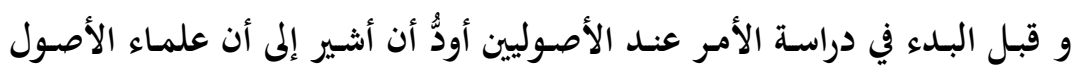

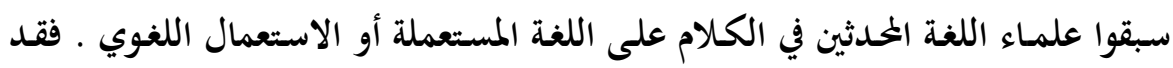

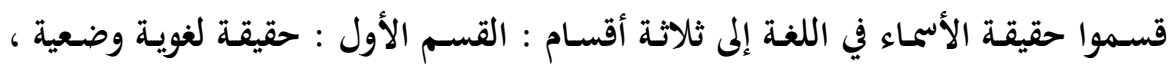

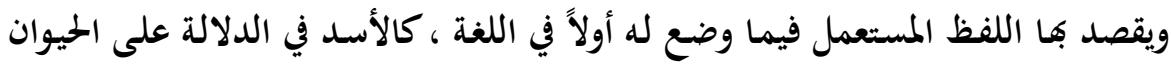
المفترس ، الإنسان في الدلالة على الحيوان الناطق ، وهذه الحقيقة هي الأسبق إلى الذهن

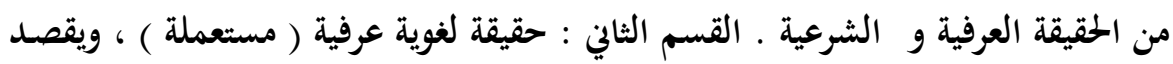

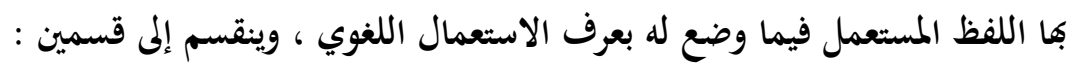
1- إقيقة عرفية عامة، وتنقم إلى قسمين :

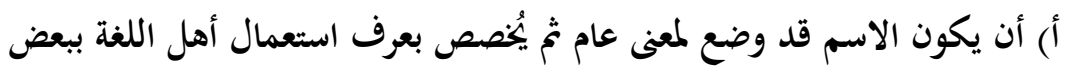

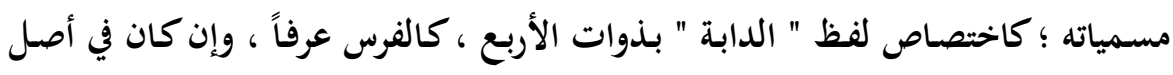

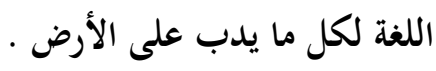
ب) أن يكون الاسم في أصل اللغة بمعنى ، ثُ يُشتهر في عرف استعمالهم بمعنى غير

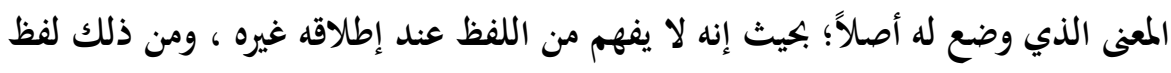


" الغائط " فإنه يطلق في أصل اللغة على الموضع المطمئن والمنخفض من الأرض ، ثم اشتهر

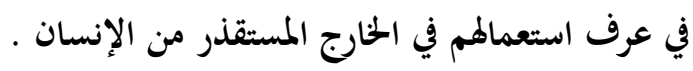

r - حقيقة عرفية خاصة ، ويقصد بها المصطلحات الخاصة بأرباب كل فن . القسم

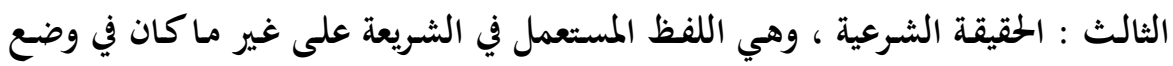

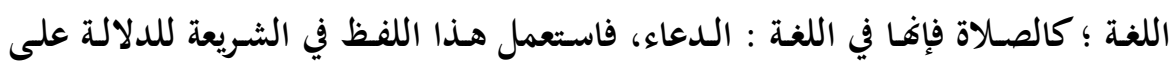
أقوال وأفعال مخصوصة فصارت حقيقة فيها.'

وعلماء أصول الفقه قد تحدثوا عن الاستعمال اللغوي قبل ظهور التداولية بقرون عديدة ـ والثيار التداولي : مذهب لساني يدرس علاقة النشاط اللغوي بمستعمليه ، وطرق لهول وكيفيات استخدام العلاقات اللغوية بنجاح ، والسياقات والطبقات المقامية المختلفة التي

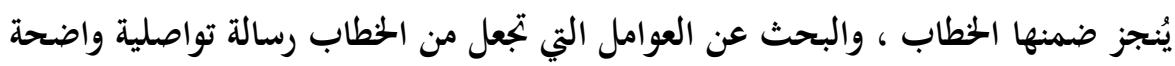

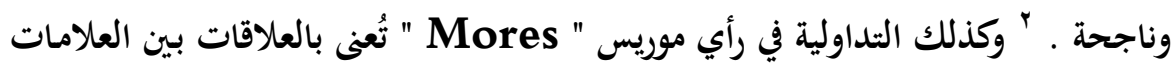

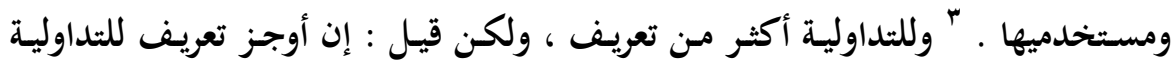
وأقربه إلى القبول هو : دراسة اللغة في الاستعمال أو في التواصل لأنه يشير إلى ألى أن المعنى

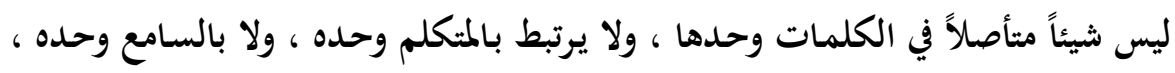

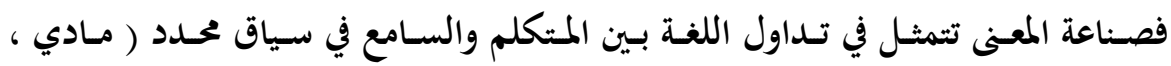

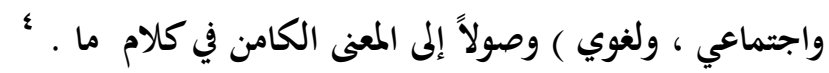
وهكذا نجد أن التداولية كانت معروفة لدى علماء الأصول ، ولكنها لم تكن تحمل هذه التسمية الحديثة ، فتراثنا العربي القديم بـ كثير من المعلومات التي تظهر بعد ذلك ذلك في

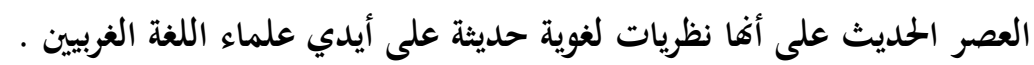

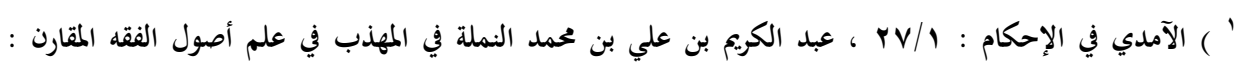
1100 ، 11 1199 ، $11 \leqslant 1 / r$

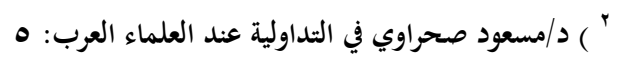

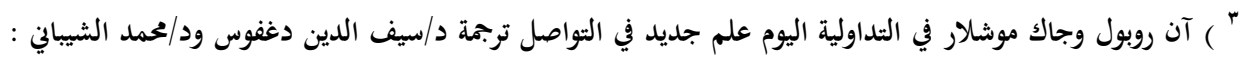


ويقع مفهوم " الأفعال الكلامية " في موقع متميز من هذا المذهب اللساني الجديد

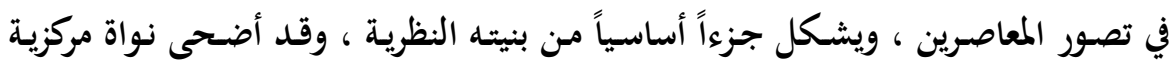

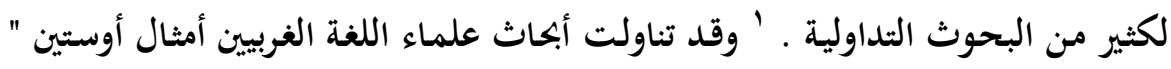

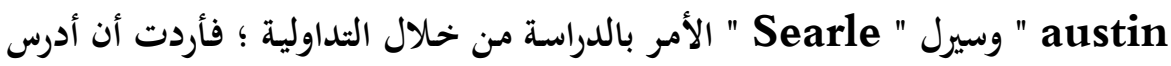
الأمر عند الأصوليين في ضوء هذه النظرية اللغوية الحديثة ؛ وذلك لأبين أن تراثنا العربي

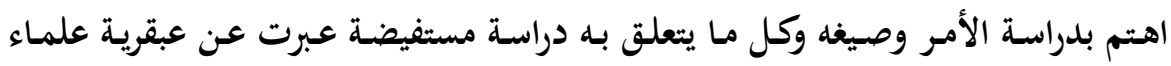

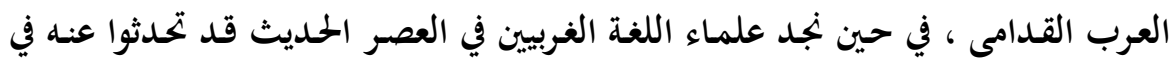
عبارات قصيرة ومختصرة .

فلأمر في اللغة : بمعنى الطلب ، وجمعه أوامر ، والأمر نقيض النهي ، وقيل : الأمر

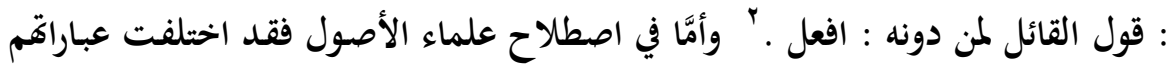

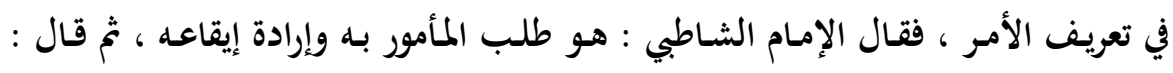

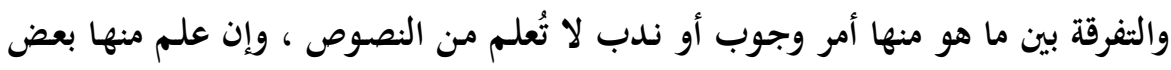

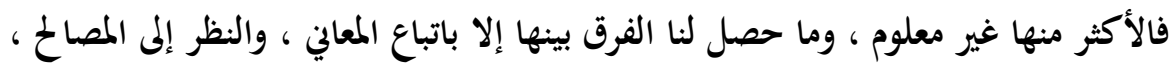

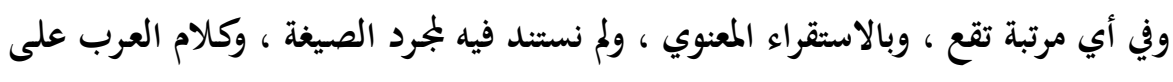

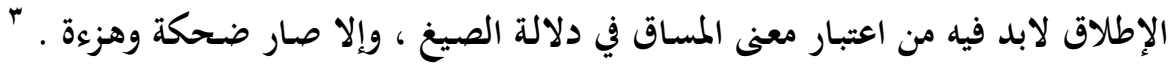

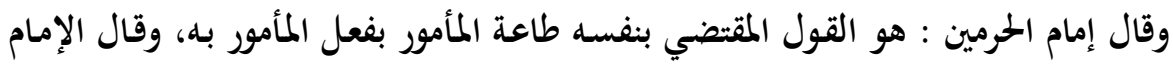

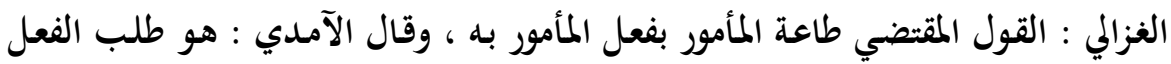

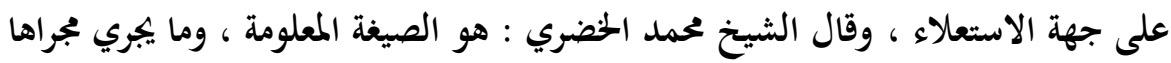

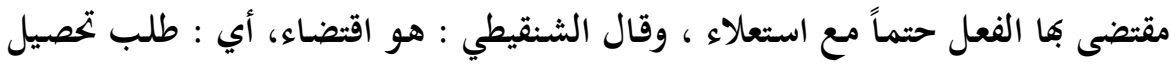

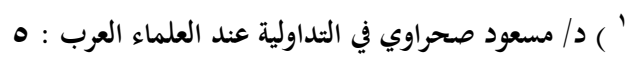
"' ") ابن منظور في اللسان ( أمر ) ، أممد بن عحمد بن علي الفيومي في المصباح المنير (أمر ) ، الشريف الجرجاني في كتاب

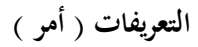

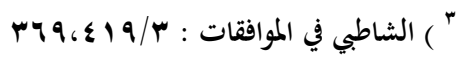


فعل غير كفٍ مدلول عليه بغير كفّ . ' ولا فرق في الطلب بين جازم وغيره ، وإن كان الأمر

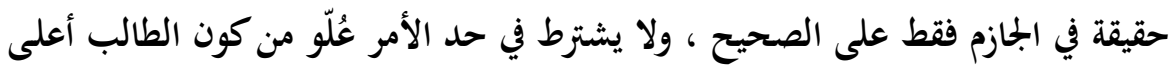

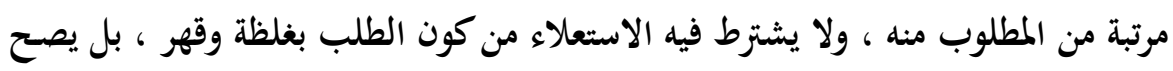

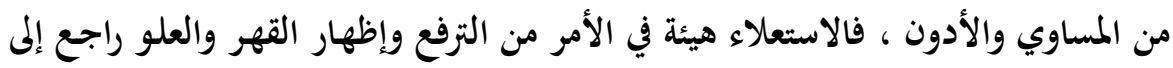

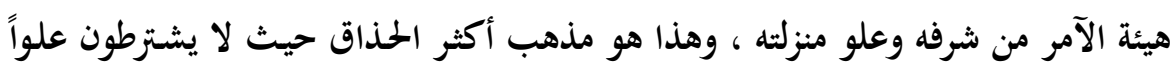
ولا استعلاءً .

فالراجح من قول الأصوليين أن الأمر لا يشترط فيه الاستعلاء ، فيصح أن يصدر

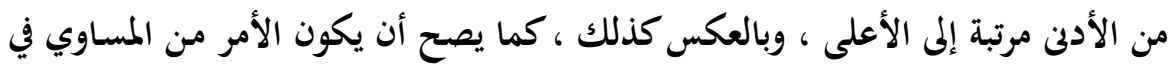

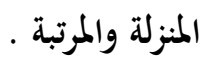

ومما يدل على عناية علماء الأصول بدراسة الأمر أفهم قد اختلفوا فيما بينهم ، كاهـ

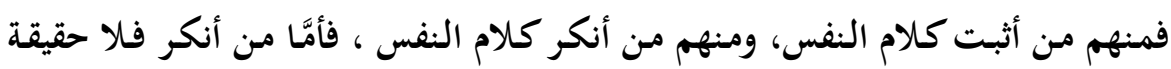

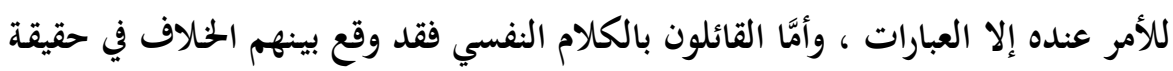

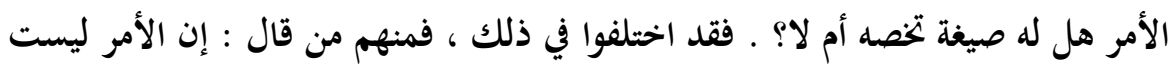

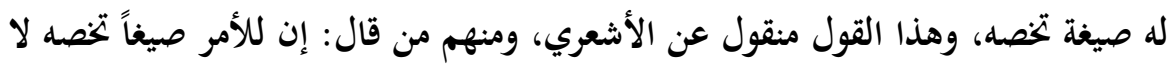

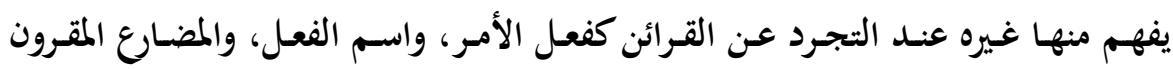

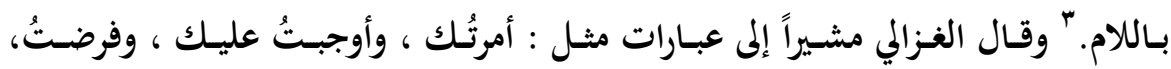

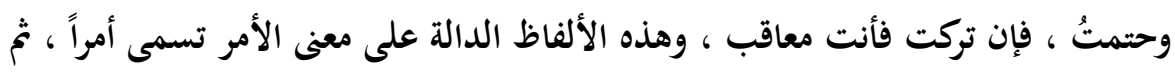

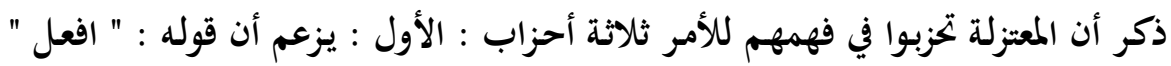

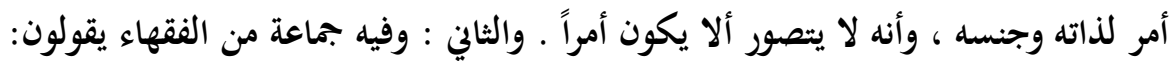

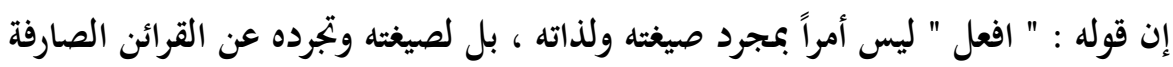

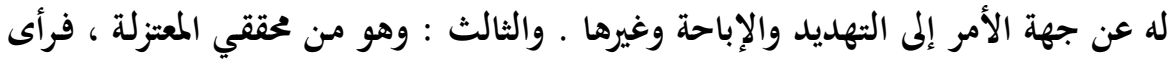

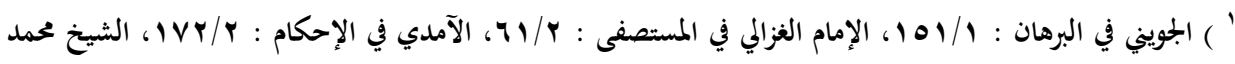

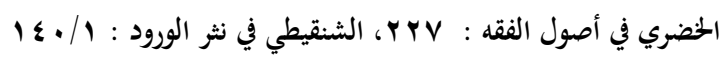

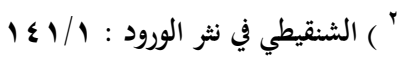

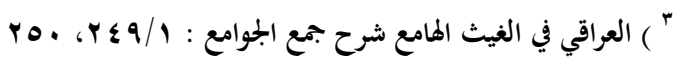




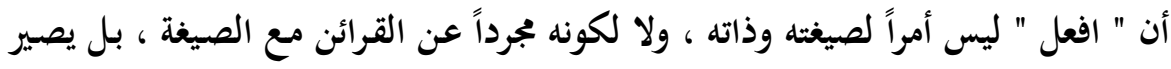

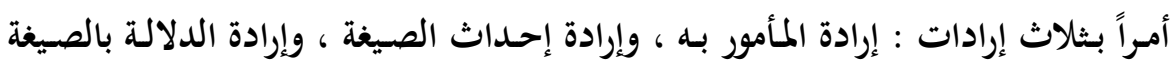

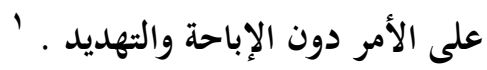

فكل ما سبق ذكره يدل دلالة واضحة على اهتمام علماء العرب القدامى بدراسة

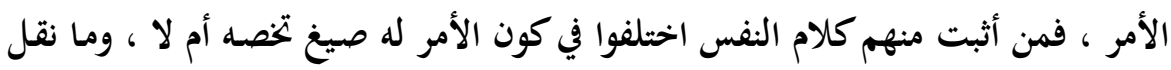

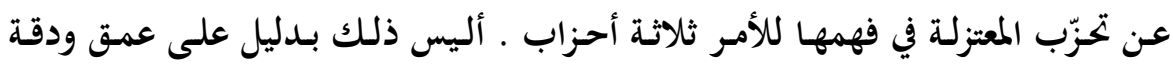

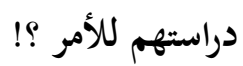

وللأمر أربع صيغ موضوعة في اللغة للدلالة على طلب الفعل جزماً إذا تجردت عن

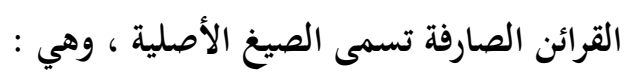

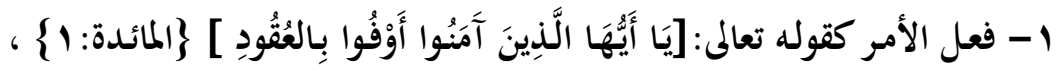

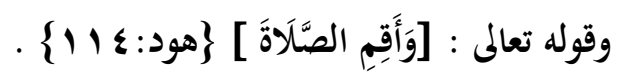

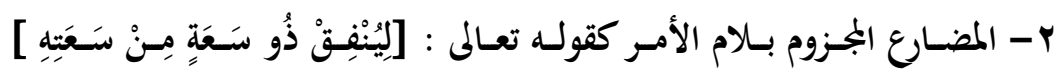
. $\{v:$ : الطَّلاق

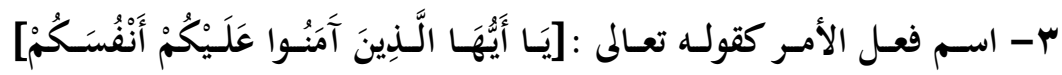

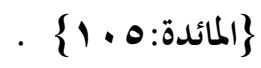

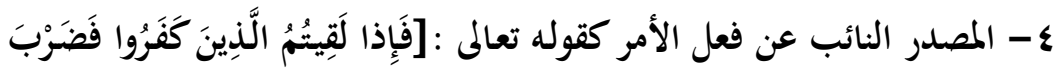

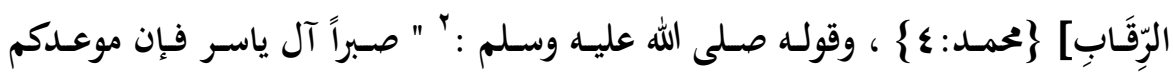

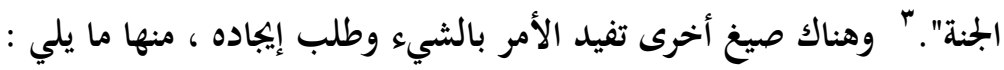

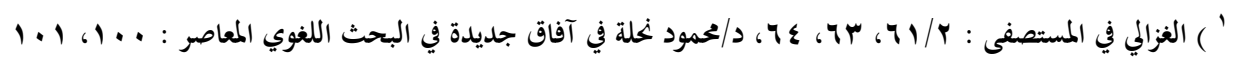

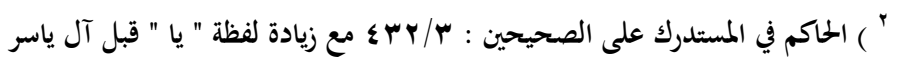

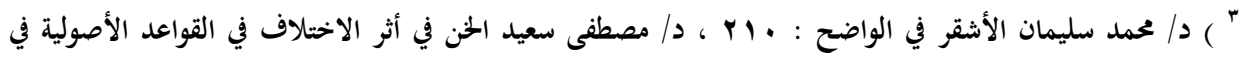

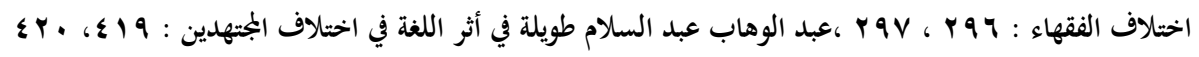




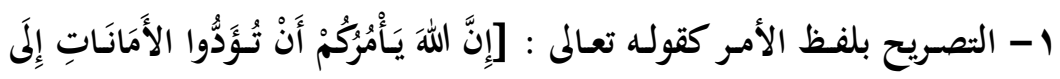

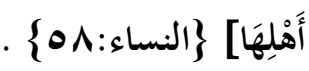

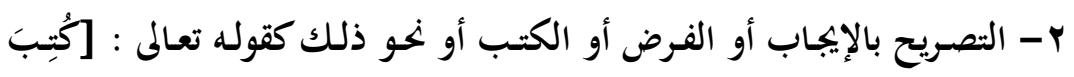

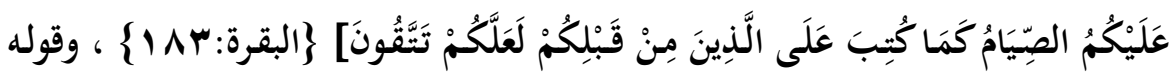
عليه السلام :' " إن الله فرض عليكم الحجج فحجوا ل. . " .

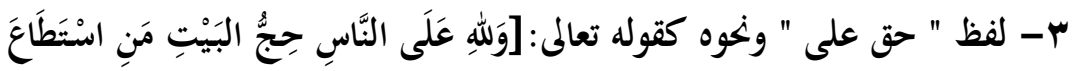

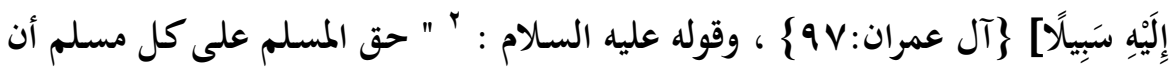
يغتسل في كل سبعة أيام يوماً ؛ يغسل فيه رأسه وجسده " . .

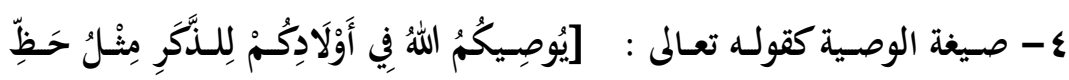
الأُنْيَيْنِ $\{$ النساء:11

ه- كل ما فيه ترتيب ذم أو عقاب أو إحباط عمل على ترك أو نحو ذلك ، كقوله

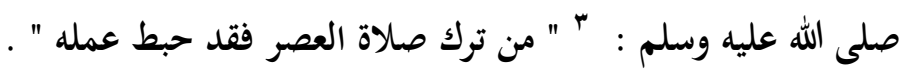
ه- قد يرد الأمر بلفظ الحبر في جملة السية أو فعلية ، كقوله تعالى : [وَالمُطَلََّّاتُ

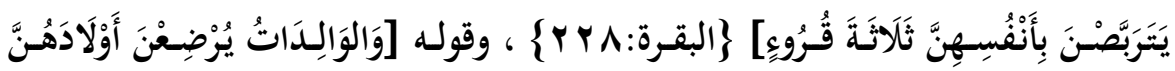

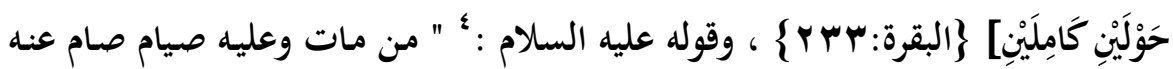

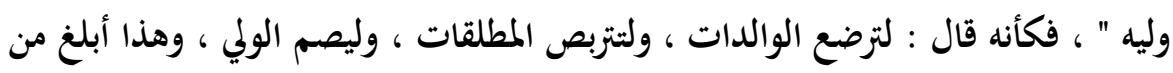

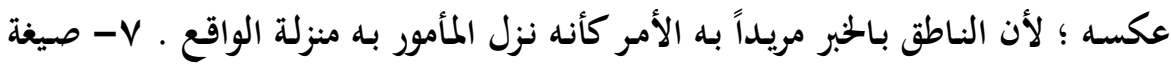

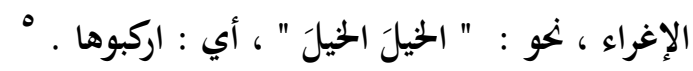

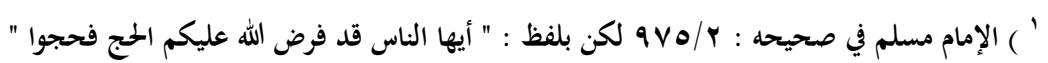

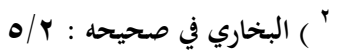

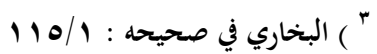

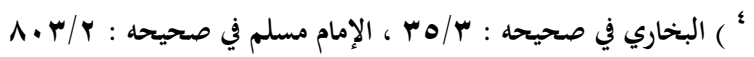

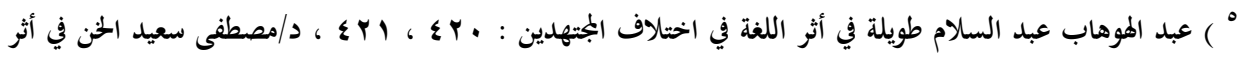

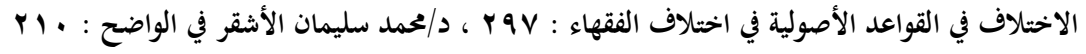


والأمر قد يستعمل لمعالٍ كثيرة ، وهي كالآتي :

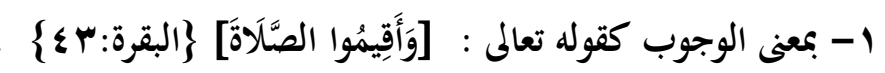

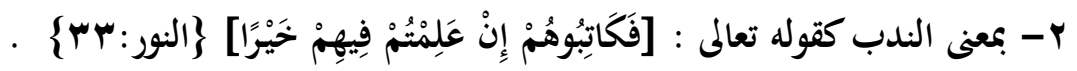

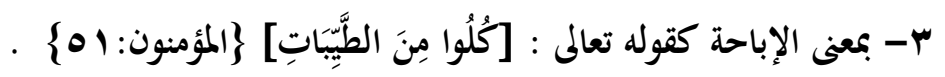

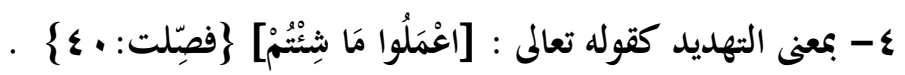

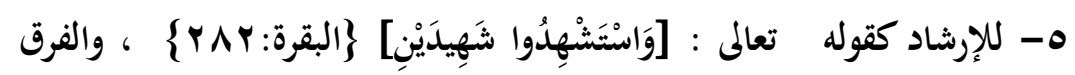
بينه وبين الندب تعلقه بمصلحة دنيوية بخلاف الندب فإن مصلحته أخروية . צ- إرادة الامتثال كقولك عند العطش : " اسقني ماءً " ، فإنه يحدث لك إرادة

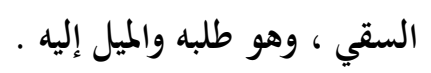

- الإذن ، كقولك لطارق الباب : ادخل ، وكأنه قسم من الإباحة .

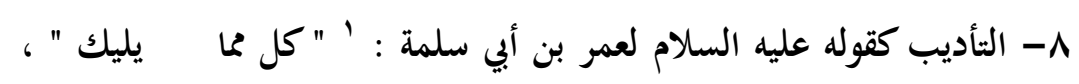

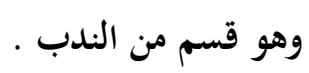

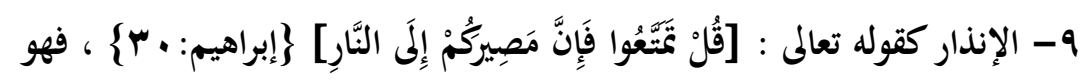

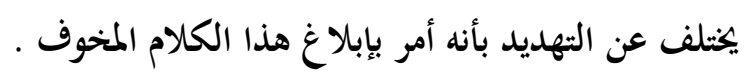

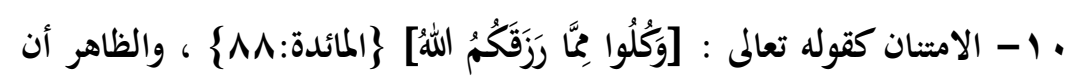

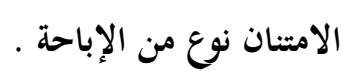

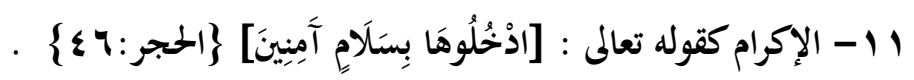

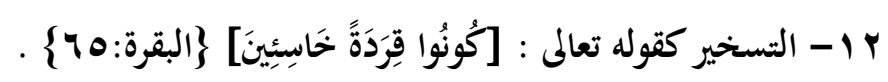

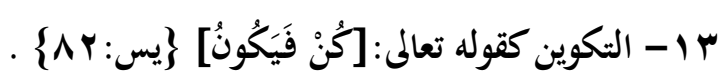

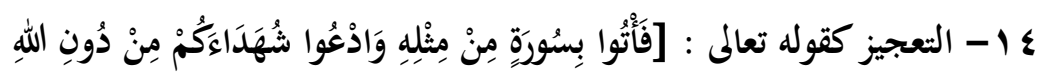




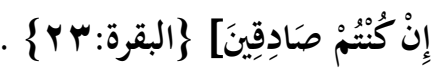

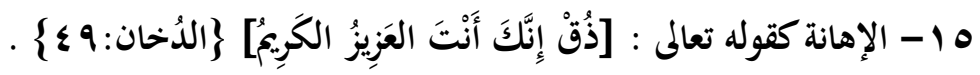

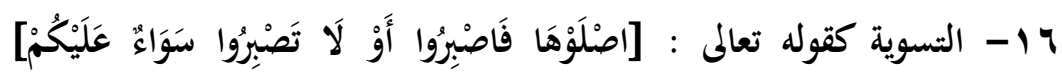

\{17: الطُّو 19$\}$

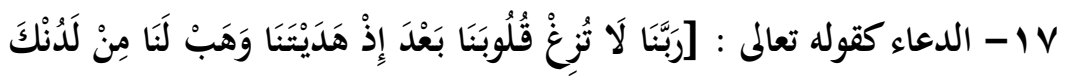

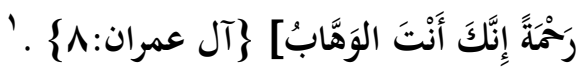

$$
\begin{aligned}
& \text { 11 - التمني كقول امرئ القيس : ' }
\end{aligned}
$$

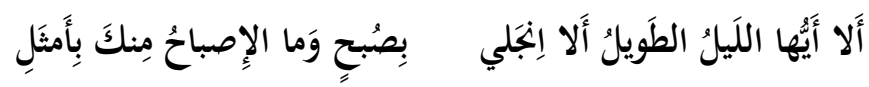

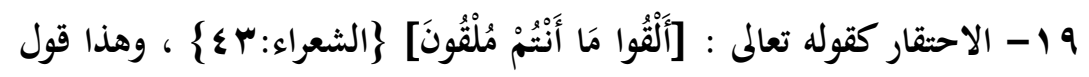

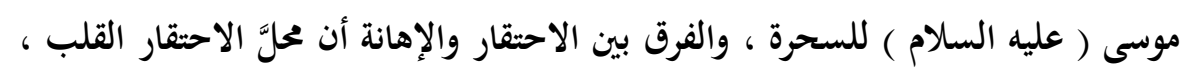

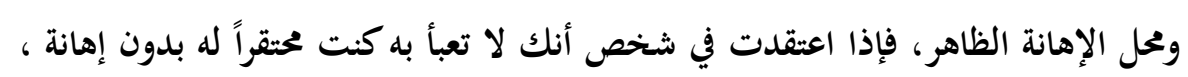

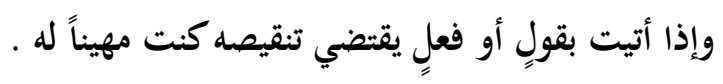

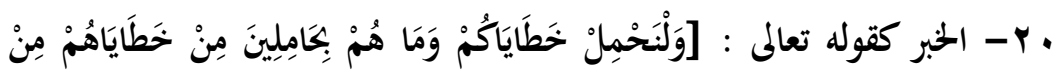

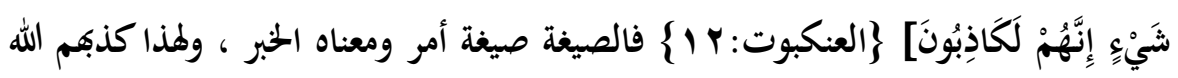

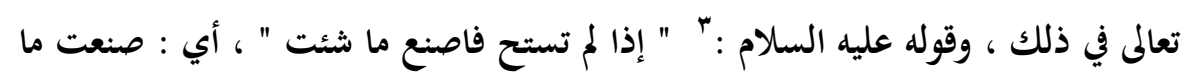

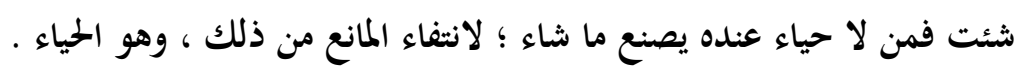

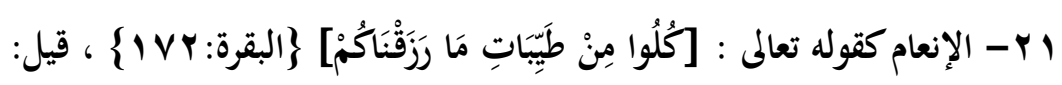

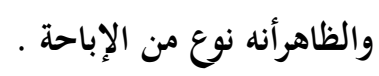

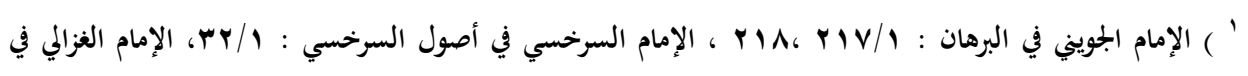

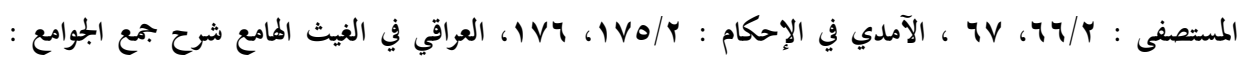

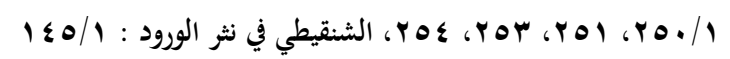

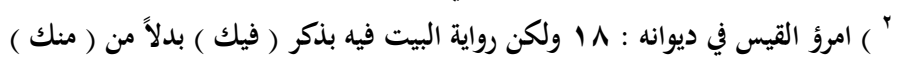

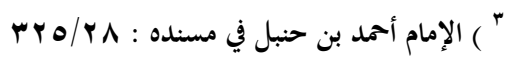




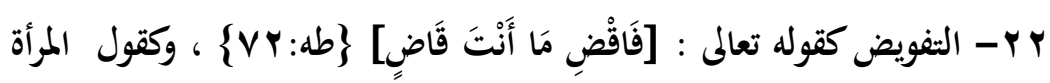

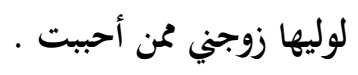

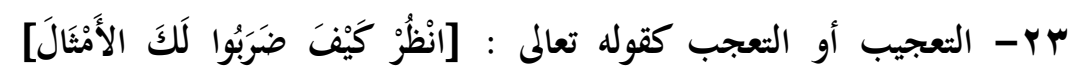

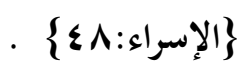

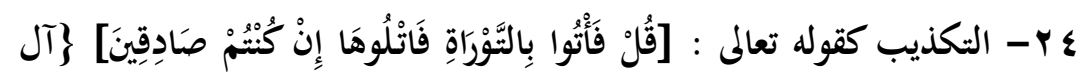

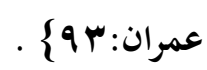

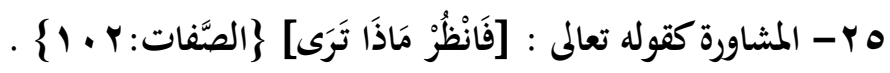

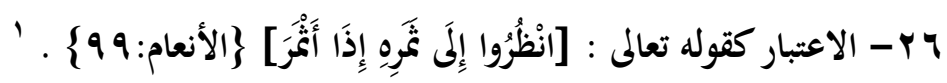

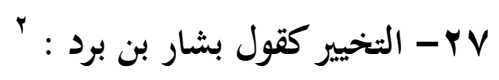

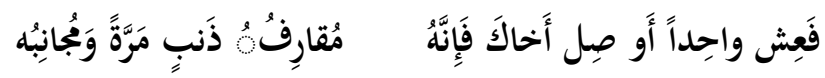

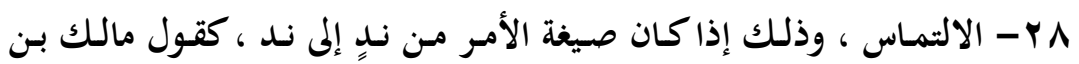

$$
\text { الريب : }
$$

فَيا صاجبي زَحلي دَنا المَوَتُ فَانَزِلا

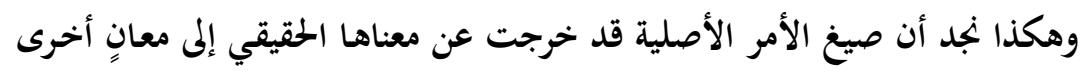

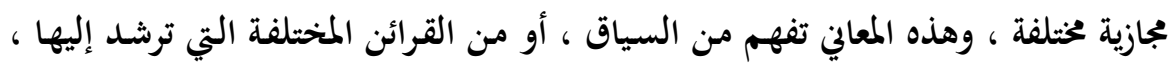

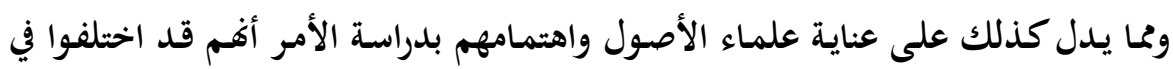

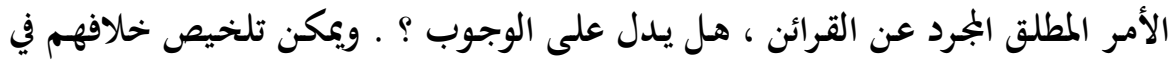

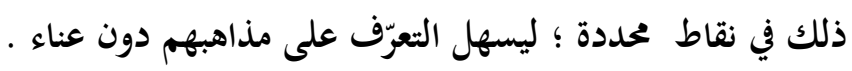

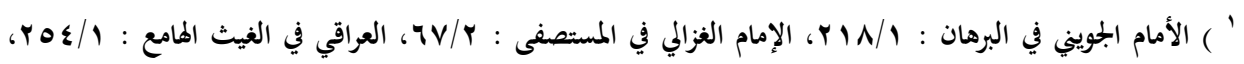

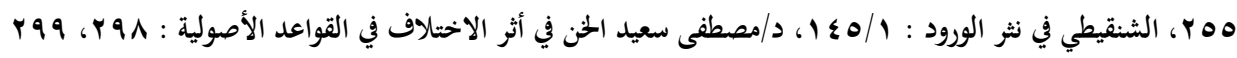

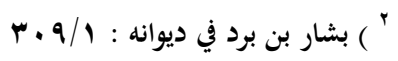

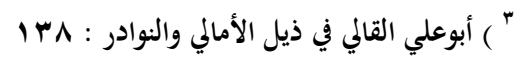

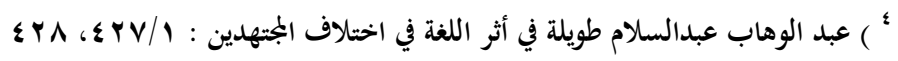


فقد اختلفوا في دلالة الأمر المطلق الجردد عن القرائن على مذاهب ، ومن أشهر هذه

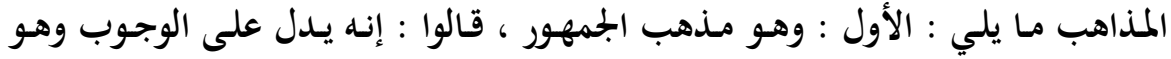
حقيقة فيه ، ولا ينصرف إلى غيره من المعاني إلا بقرينة . الثاني : أن الأمر حقيقة في الندب.

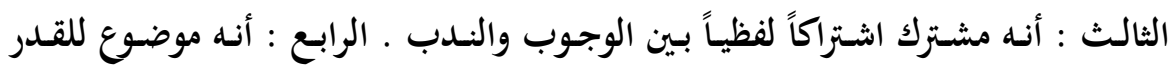

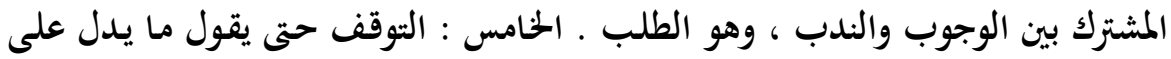

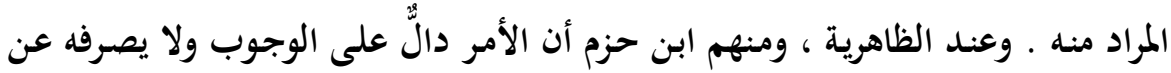

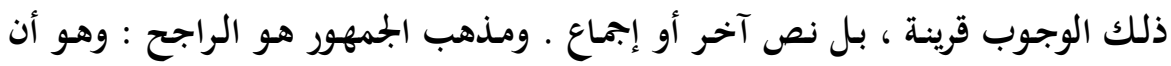

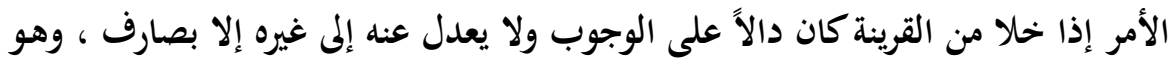

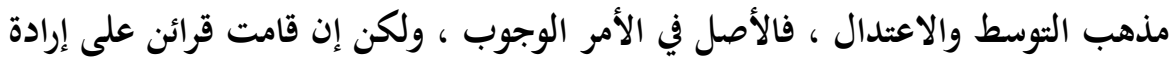

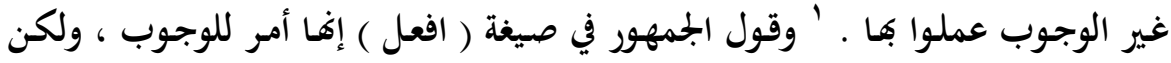

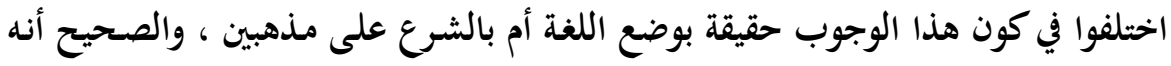

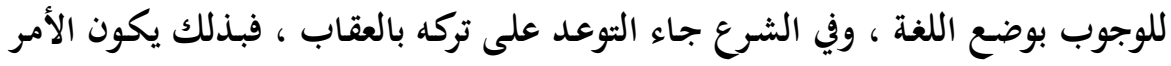

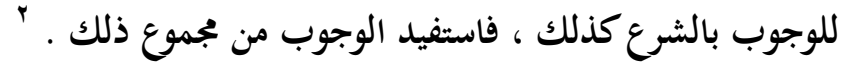
ومما سبق يتضح لنا وضوحاً جلياً أن الراجح هو أن الأمر المطلق الججرد عن القرائن

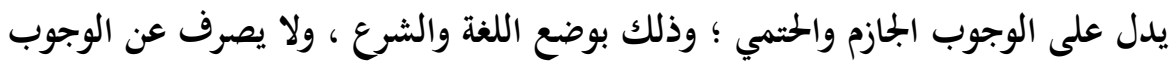

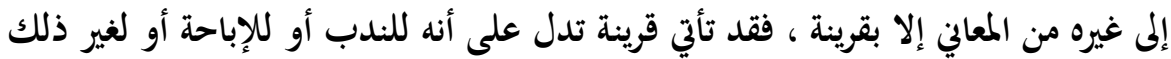

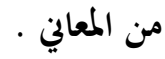

والأدلة على أن الأمر المطلق للوجوب في الشرع كثيرة ، منها : قوله [فَلْيَحْذَرِ

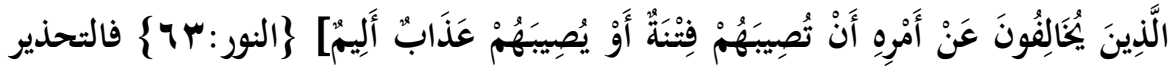

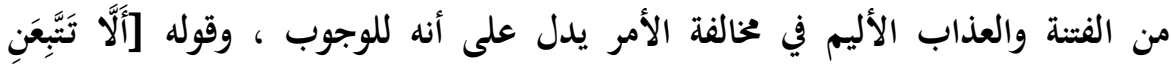

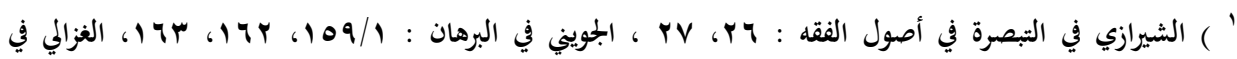

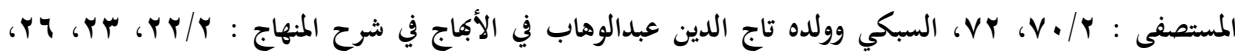

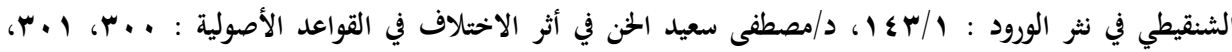

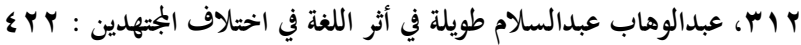

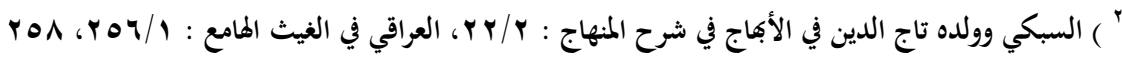


أَفَغَصَيْتَ أَمْرِي] \}طه:بهج\{ ، فالآية تبين أن مخالفة الأمر معصية ، وفي هذا دليل على أن

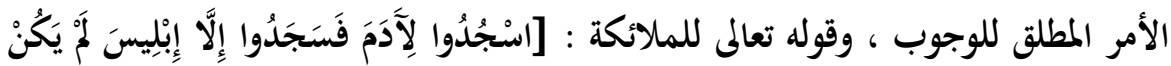

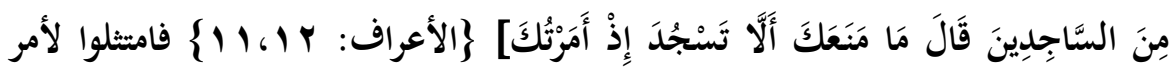

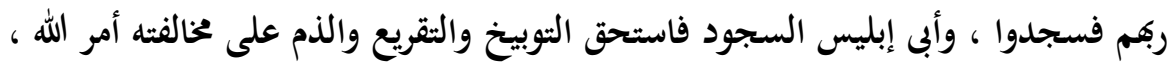

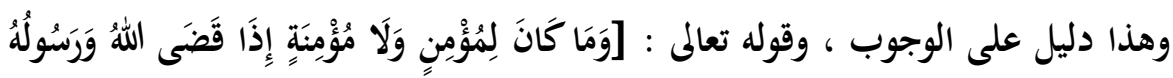

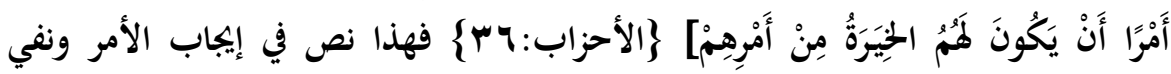

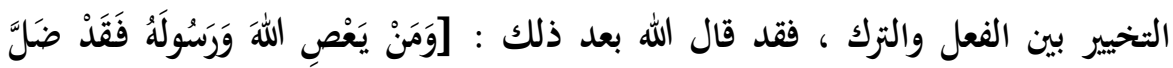

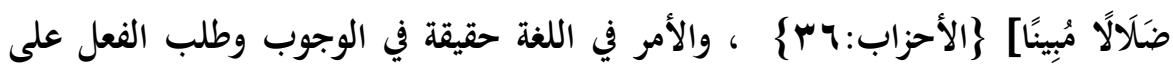

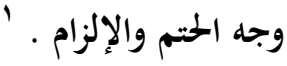

فلأمر المطلق الجزرد عن القرائن يدل على الوجوب وطلب الفعل على وجه الحتم

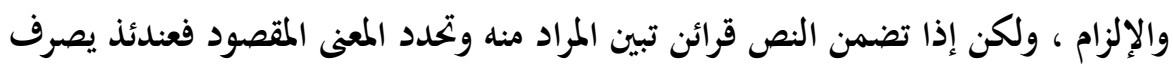

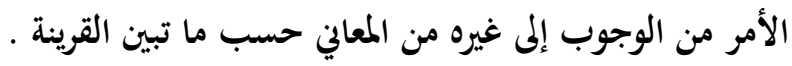
ومما يدل كذلك على عناية الأصوليين بدراسة الأمر أفم اختلفوا في الأمر المطلق ،

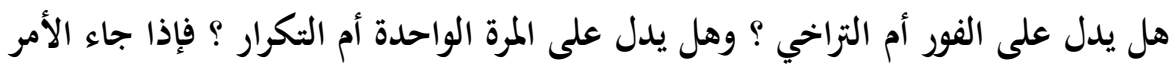

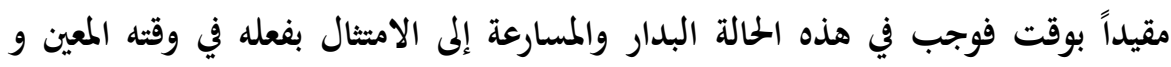

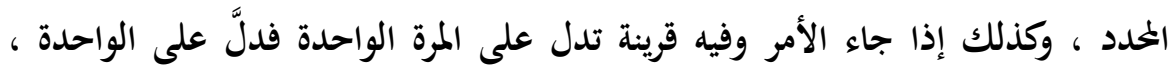

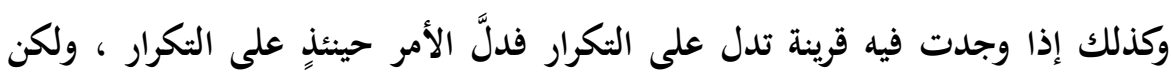

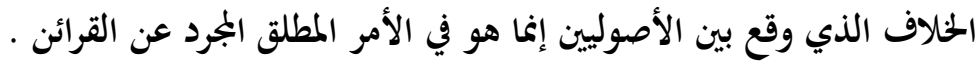

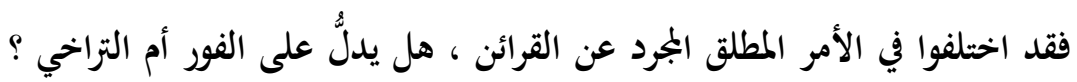

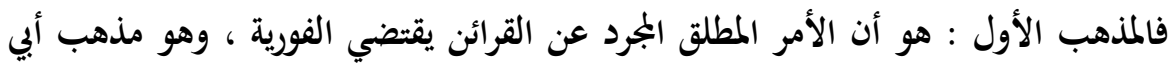

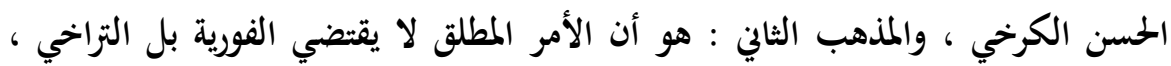

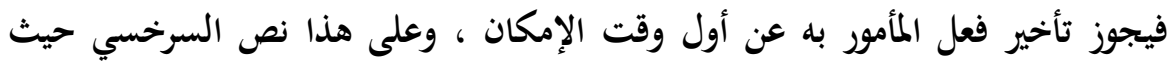

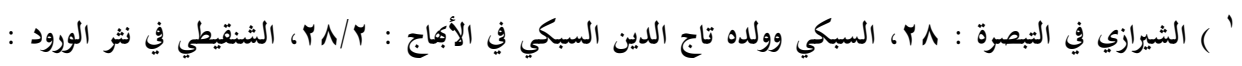

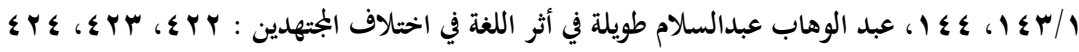


قال: " الذي يصح عندي فيه من مذهب علمائنا - رمهم الله - أنه على التراخي ، فلا

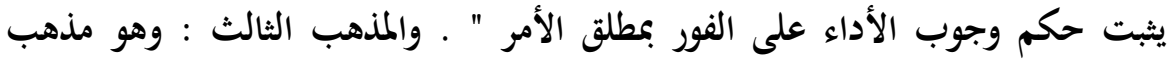

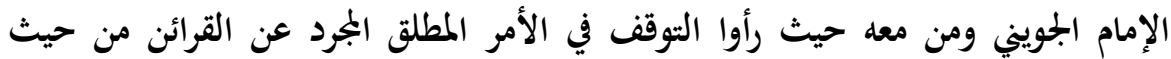
اقتضاؤه الفور أو التراخي ، فلابد عندهم من توفر قرينة تصرفه إمَّا إلى الفور وإمَّا إلى إلى التراخي ـ والراجح في ذلك هو أن الأمر يقتضي الفورية ، ودليل ذلك من القرآن قوله

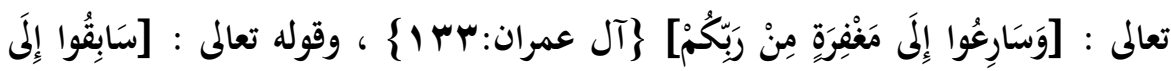

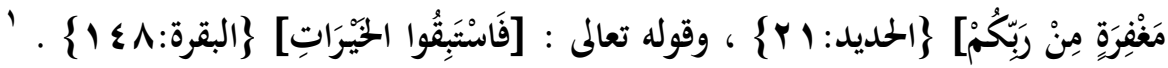
وكذلك ما جاء في صحيح البخاري من قول النبي ( صلى الله عليه وسلم ) لأصحابه في

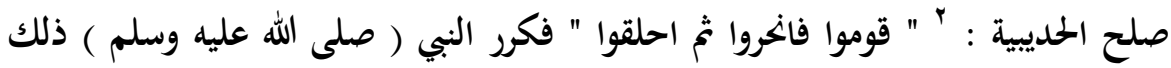
ثلاث مرات فلما لم يقم منهم أحد دخل على أم سلمة ، فذكر لها ما لقي من الناس ... إلى لى

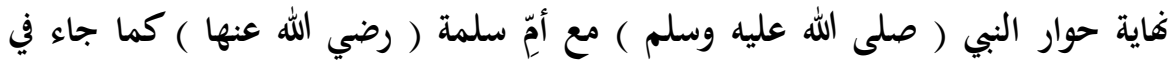

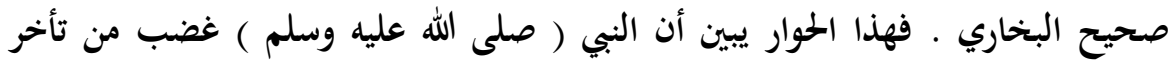

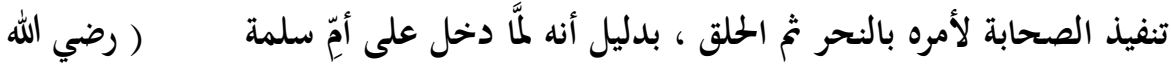

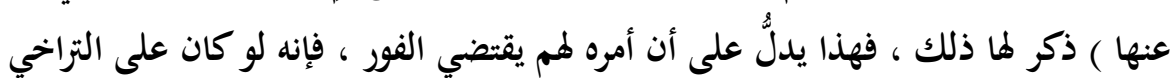

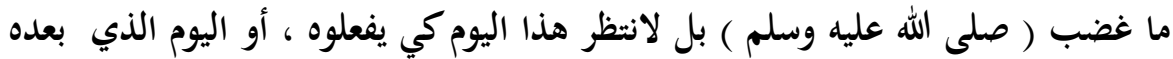

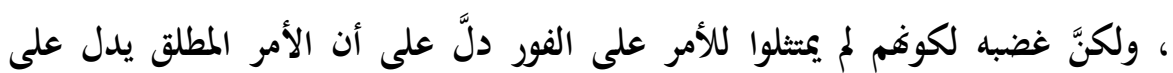
الفورية ، وكذلك الآيات السابق ذكرها جاء فيها ألفاظ المسارعة والمسابقة بصيغة الأمر الذي يدل على الفورية ، والأمر المطلق يدل على الفورية كذلك بوضع اللغة ، ولكن إذا

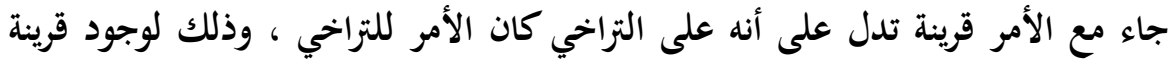
تدل على ذلك .

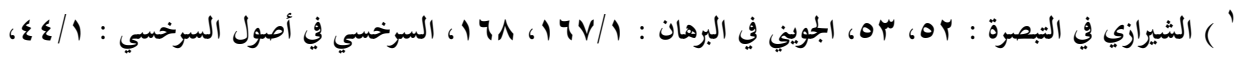

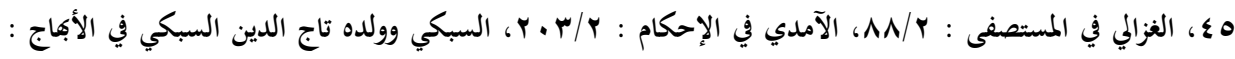

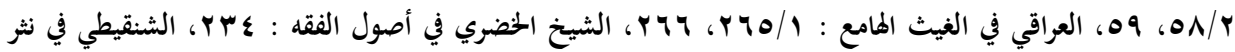

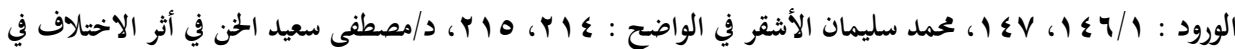

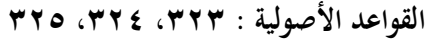

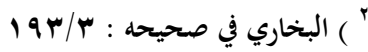


وكذلك اختلف الأصوليون في الأمر المطلق المجرد عن القرائن ، هل يدل على المرة

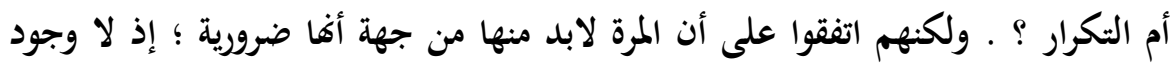
للماهية إلا أن يوجد بعض أفرادها على الأقل ، لا من جهة أفها مدلول اللفظ ، وأمَّا

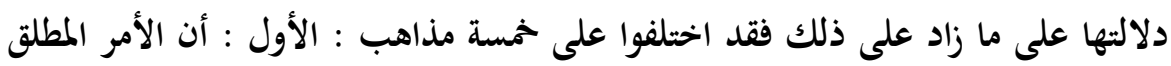
يوجب التكرار المستوعب لجميع العمر إلا إذا قام دليل يمنع من ذلك الك ، وهو الختيار أبي

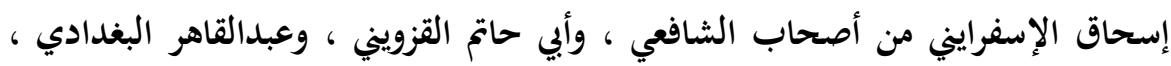

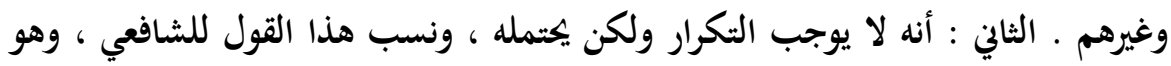

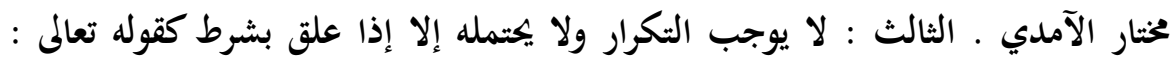

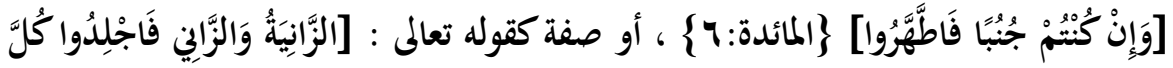

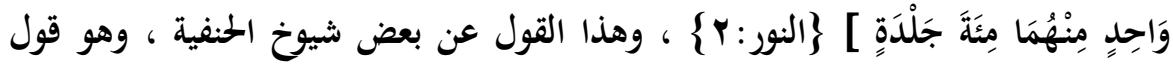
لبعض الشافعية ـ. الرابع : أنه لا يوجب النكرار ولا يحتمله سواء أكان مطلقاً أم معلقاً

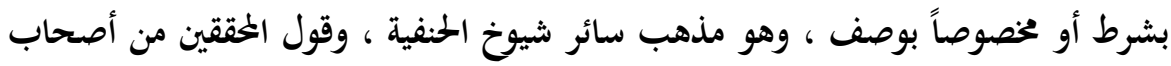

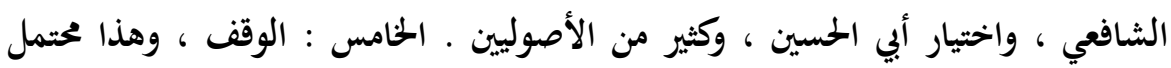

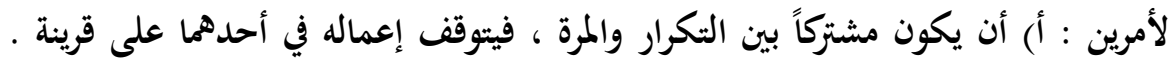

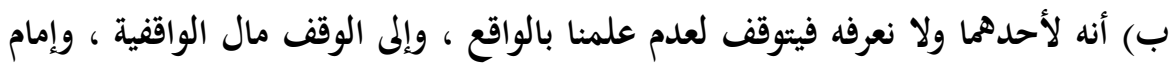

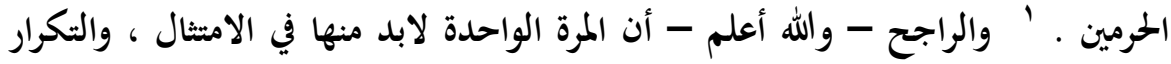
محتمل ؛ فإن اقترن بالأمر قرينة أشعرت بإرادة المتكلم التكرار حمل الأمر على التكرار ، وإلا كان الاقتصار على المرة الواحدة كافياً .

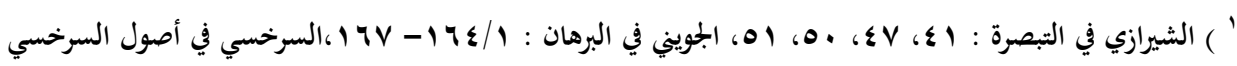

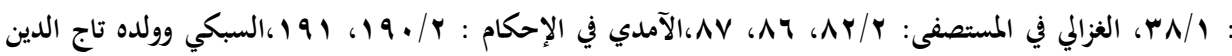

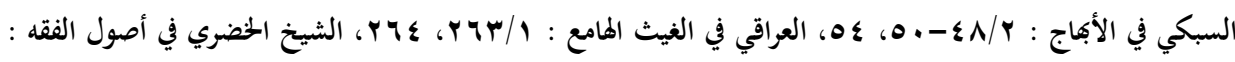

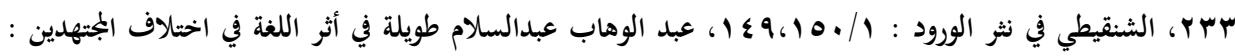

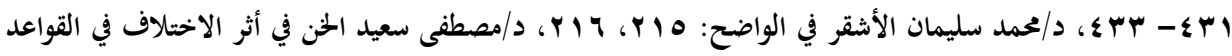


ومما يدل على عناية الأصوليين بدراسة الأمر دراسة مفصلة وشاملة ودقيقة أفم

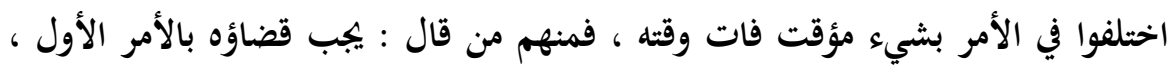

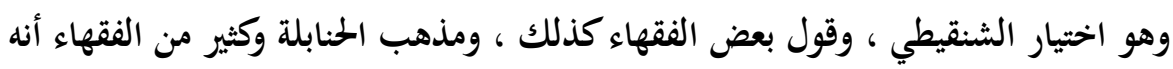

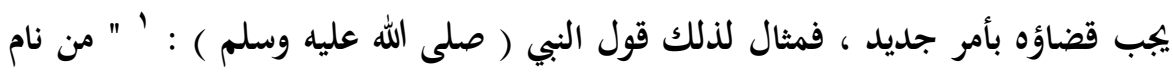

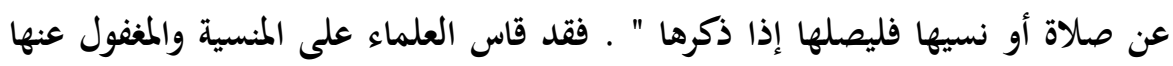

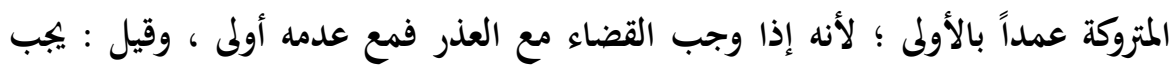

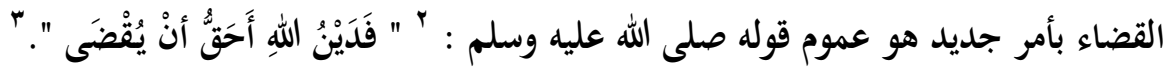
والراجح من هذين المذهبين - والله أعلم - هو أنه يجب القضاء بأمر جديد ، وهو

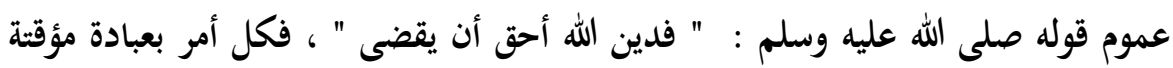

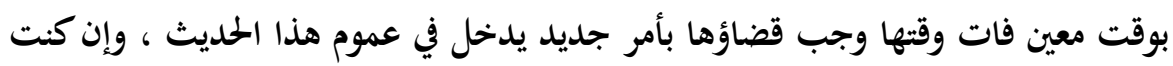

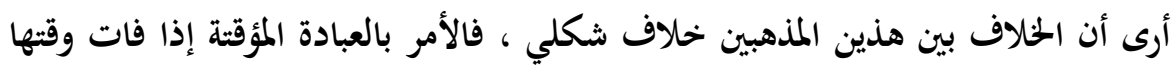

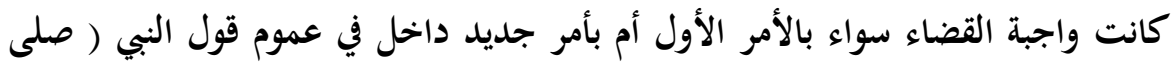

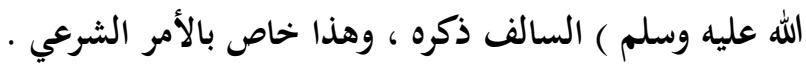
وكذلك اختلف الأصوليون في الأمر بالشيء بعد المنع أو الحظر على مذاهب ،

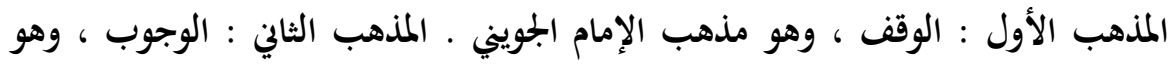
قول الحنفية ـ المذهب الثالث : الإباحة ، وهو قول بعض أصحاب الشافعي ، وقول

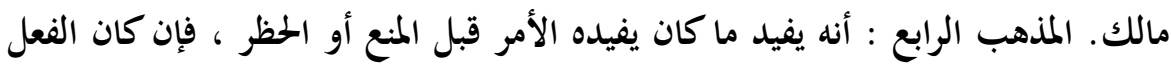

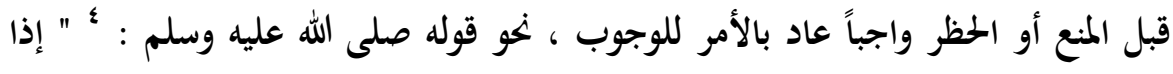

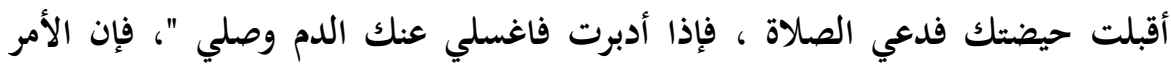

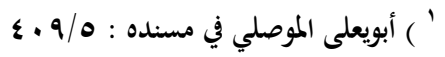

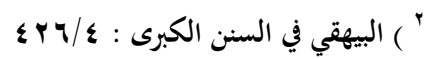

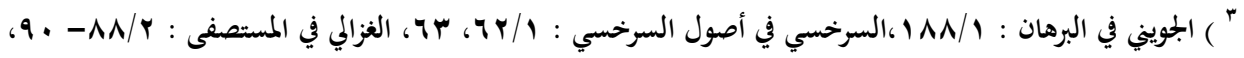
" ) البخاري في صحيحه : / هـه ولكن بلفظ ( فإذا أقبلت حيضتك فدعي الصلاة وإذا أدبرت فاغسلي عنك الدم ثم 
(صلي) للوجوب ؛ لأن الصلاة كانت قبل امتناعها بالحيض واجبة ، وإن كان الفعل قبل المنع مستحباً عاد بالأمر إلى الاستحباب ، مثل : ' " كنت فيتكم عن زيارة القبور ألا لأل

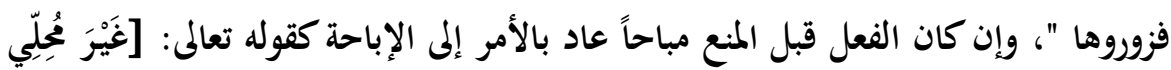

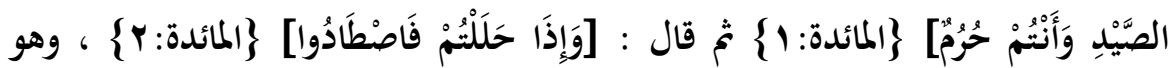

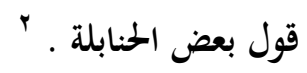

والراجح من هذه المذاهب - والله أعلم - هو المذهب الرابع ، وهو أن الأمر بعد

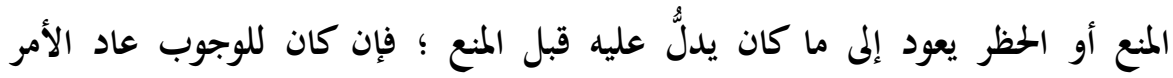

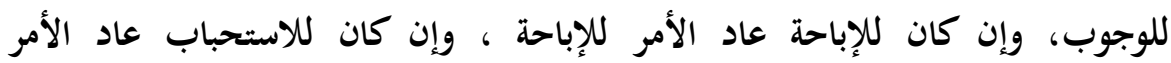

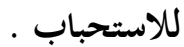

ومما يدل على عناية الأصوليين بدراسة الأمر أفم تحدثوا عن شخصٍ أمر شخصاً

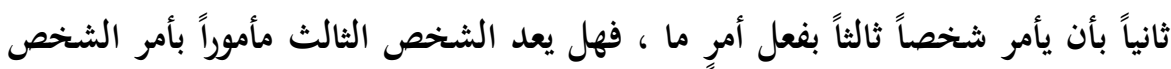

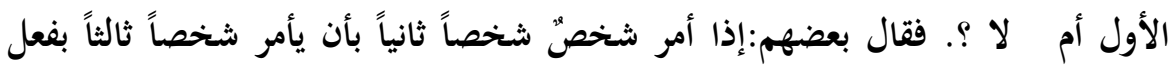

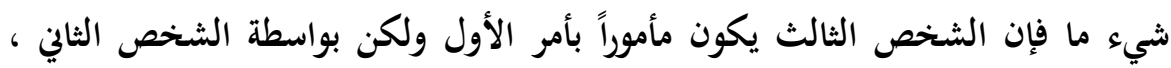
ولهذا القول وجه من النظر ، وقال آخرون : الأمر بالأمر بالشيء ليس أمراً بالشيء إلا إذا لـا

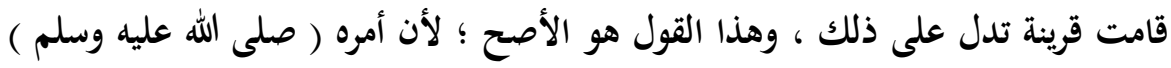

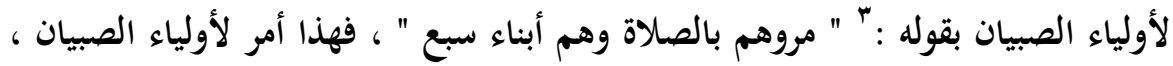
وليس أمراً للصبيان ؛ لأن الخطاب موجه لمم وليس للصبيان ، وأمَّا قوله ( صلى الله عليه

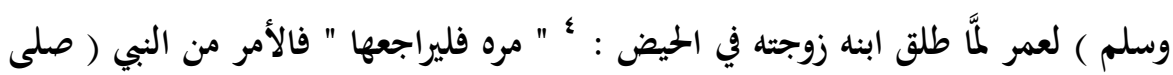

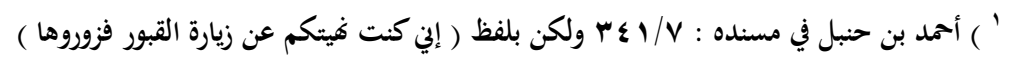

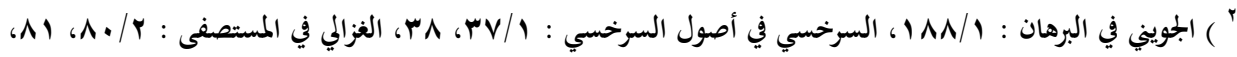

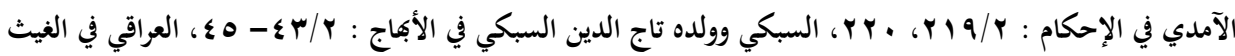

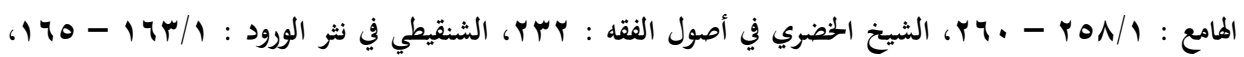

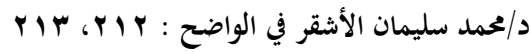

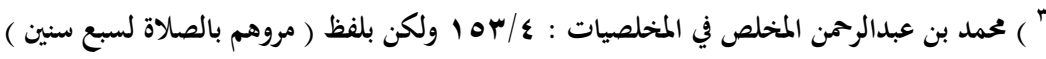

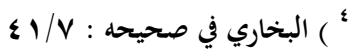


الله عليه وسلم ) متوجه لابن عمر ؛ وذلك لوجود قرينة تدل على ذلك ، وهي لام الأمر في

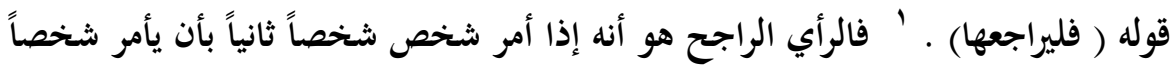

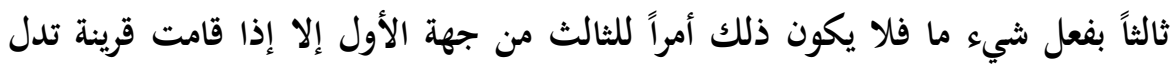

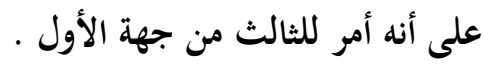

وكذلك تحدث علماء الأصول في مسألة هل يدخل الآمر في الأمر أم لا ؟ فمنهم

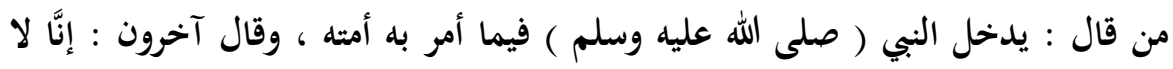

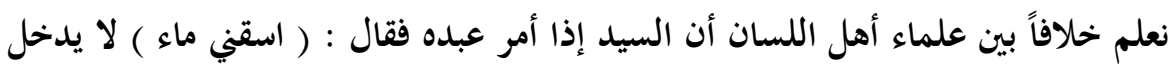

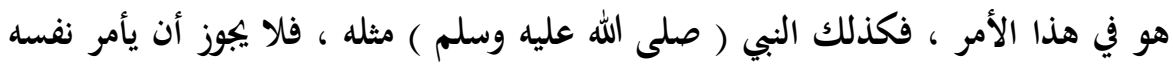

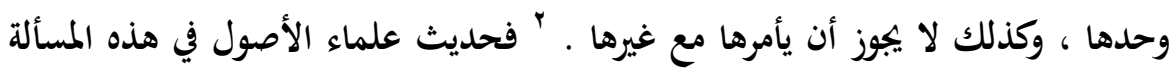

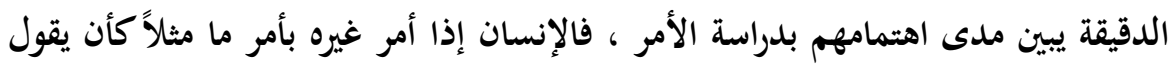
له : اركب القطار ، فهو لا يدخل في هذا الأمر بقرينة أنه هو المتكلم الآمر . وكذلك تحدث علماء الأصول عن الأمر لجماعة هل يقتضي وجوبه على كل واحد

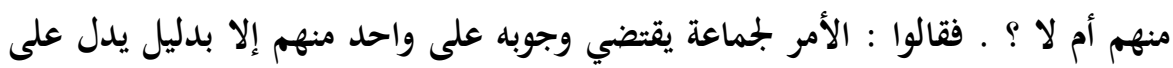

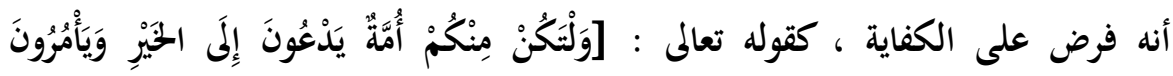

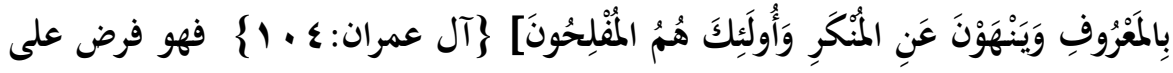

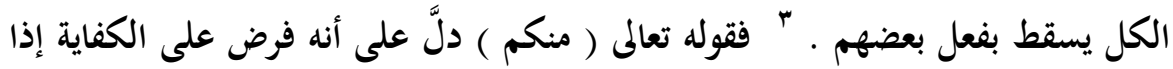

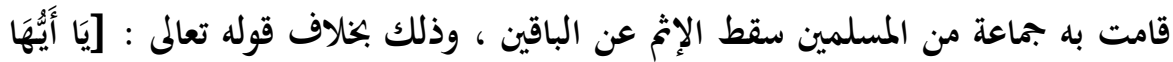

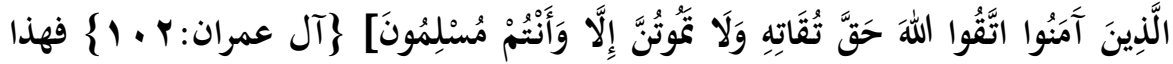

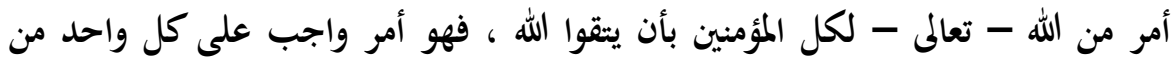

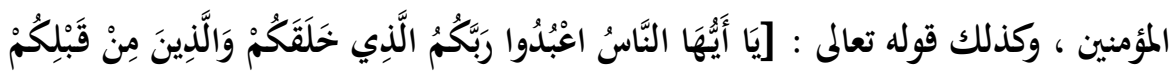

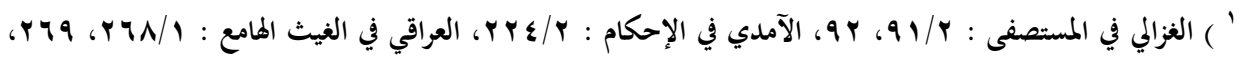

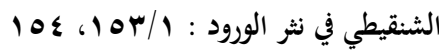

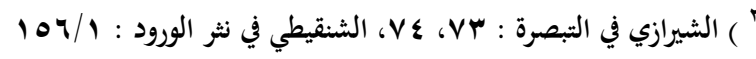

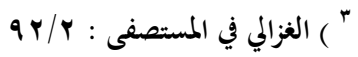




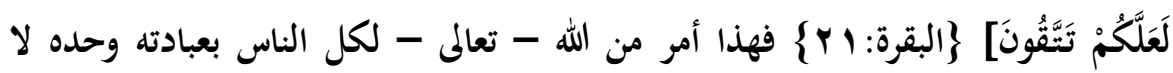
شريك له ،فهو أمر واجب على كل واحد منهم ، أي : من الناس جميعاً .

وبكسب معايير سيرل " Searle " فإن المعيار المطبَّق في خروج الأمر إلى الدعاء

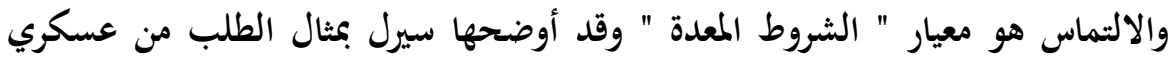

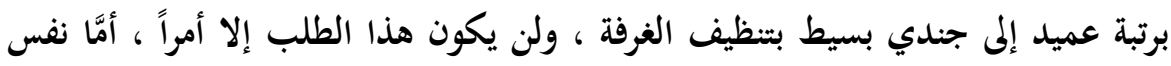

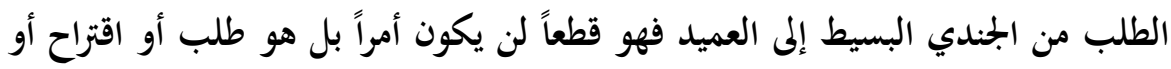

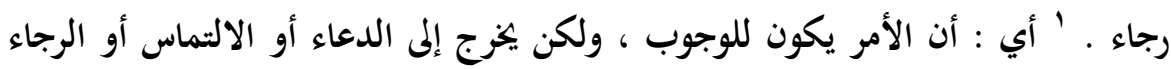

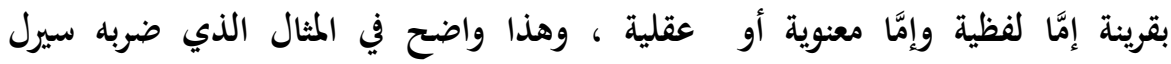

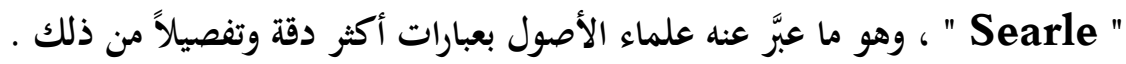
والإمام الشاطبي قسم الأمر إلى قسمين : الأول : الأمر الصريح ، وهو نوعان : أ)

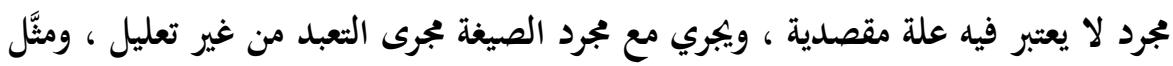

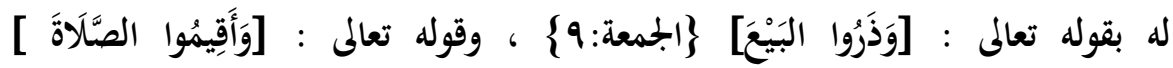

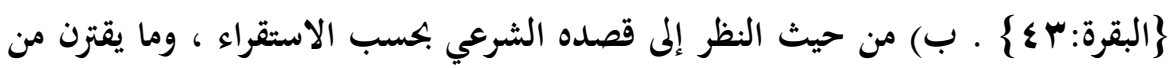

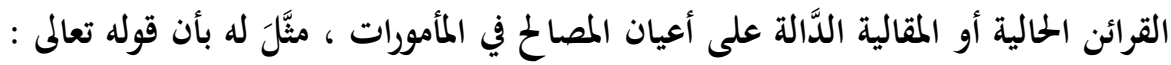

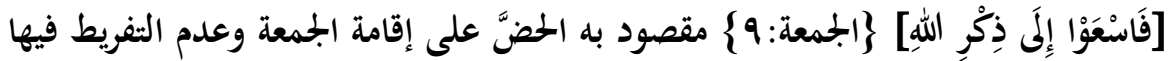

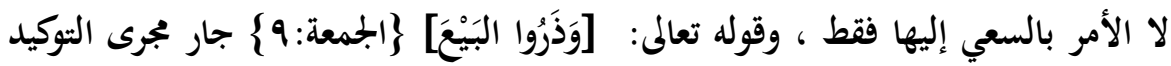

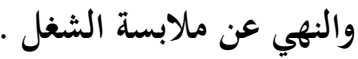

الثاني : الأمر غير الصريح ، فهو على ضروب أيضاً ، منه ما جاء إخباراً عن تقرير

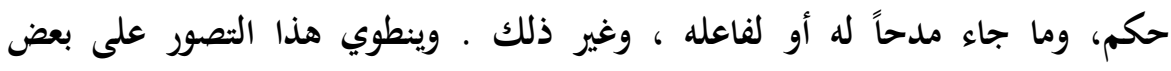

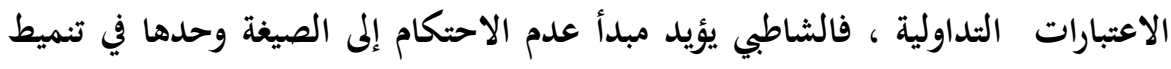

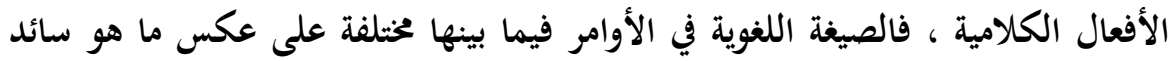

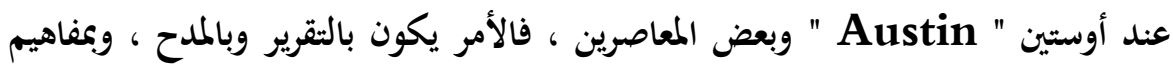
الفيلسوفين الثداوليين المعاصرين نرى أن مراعاة الجوانب التداولية في هذا الذي سميَّاه 
الشاطبي الأمر الصريح تكمن في مراعاة مفهوم القصدية في النوع الثاني من الأمر الصريح وعدم مراعاتما في النوع الأول ، أمَّا معايير سيرل فِإن الفرق بين النوعين الأول والثاني من

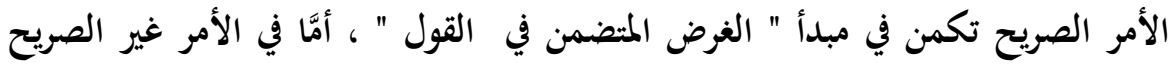

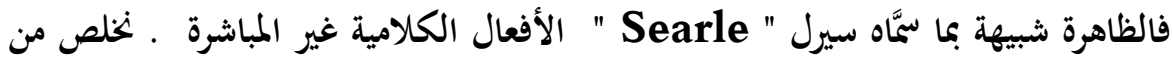

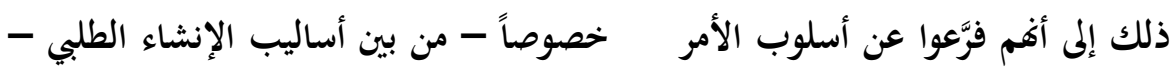

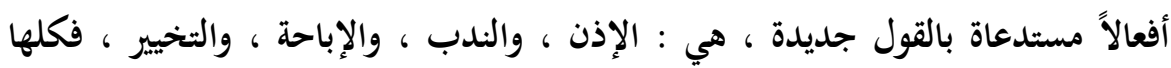

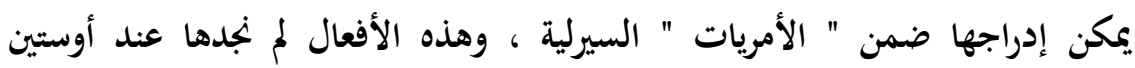
" Austin " وسيرل " Searle " المعاصرين وفق ما اطلعنا عليه من مؤلفاتمما باستثناء

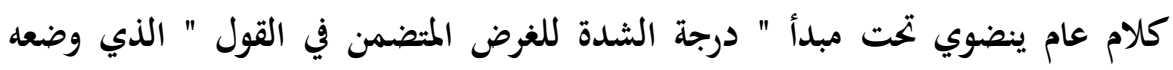

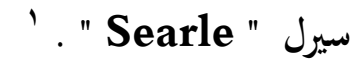

فالقوة الإنجازية خاصية المنطوقات لا الجمل ؛ فالمنطوق الواحد يمكن أن يمتلك قوى

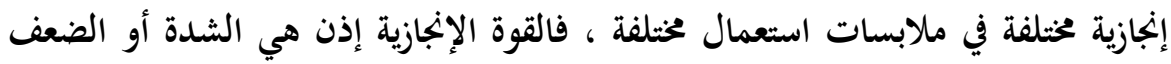
اللذان يمكن أن يعرض بأحدهما غرض إنجازي واحد في سياق بعينه من سياقات استعمال

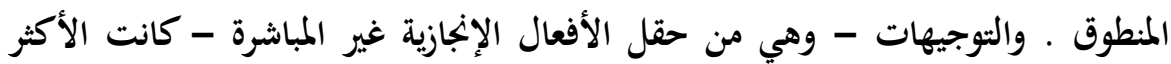
فائدة للدراسة ، وذلك أن متطلبات الكياسة أو التأدب في المخاطبات المألوفة تجعلها ثقيلة ومحيرة في إنتاج جمل أمرية بسيطة ، مثل : اترك الغرفة ، أو أدائيات صريحة ، مثل : آمرك أن تترك الغرفة ، ومن ثم يسعى الناس إلى إيجاد وسائل غير مباشرة لأداء أفعالهم الإنجازية ، فالتوجيه مثلاً أحد الأغراض الرئيسية الحمسة في تصنيف جون سيرل ، وله أغراض فراض فرعية

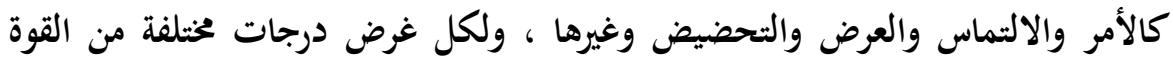
وفقاً لسياقات الاتصال ، وقد جعل أوستين لقوة علامات منها الصيغة ( أغلق الباب )

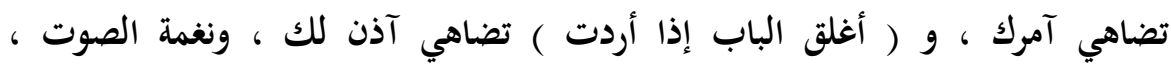

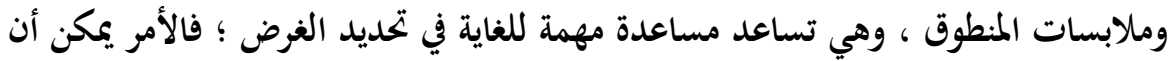


يكون أمراً أو إذناً أو عرضاً أو التماساً أو توسلاً أو اقتراحاً أو توصية أو تحذيراً ... إلح .

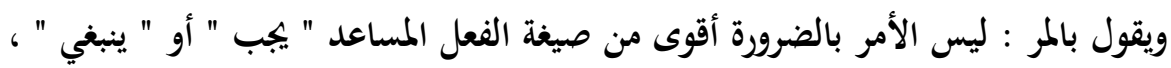

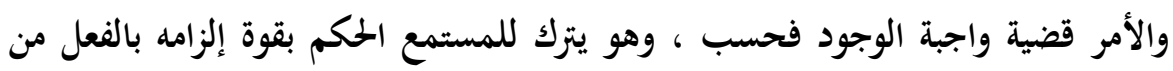
خلال الملابسات ، فإذا قال قائد لجنوده : قفوا فلن يكون هذا المناد المنطوق إلا أمراً ، ولكنه

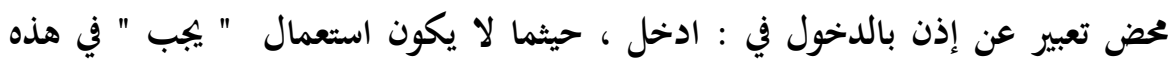

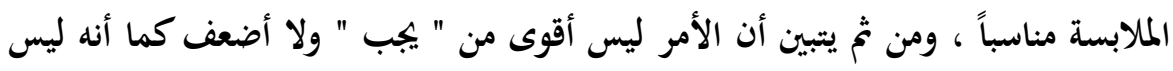

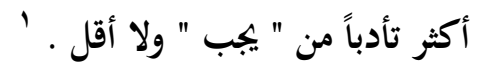
وهكذا كل ما سبق ذكره في البحث ييين مدى اهتمام الأصوليين بدراسة الأمر

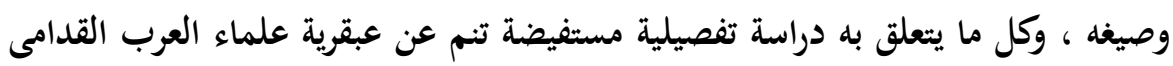

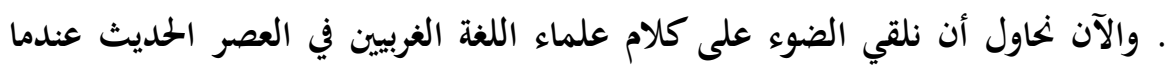

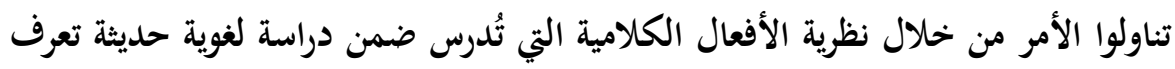

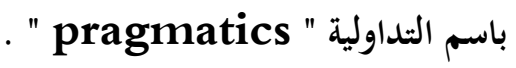
ونجد من خلال ما ترجم من كلام أوستين " Austin " في كتابه :

\section{How to do things with words}

عندما تحدث عن صيغة الفعل . قال : لقد أشرنا فيما مضى إلى ما هو مشهور جداً

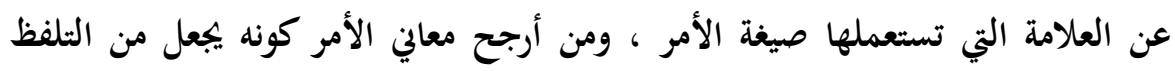

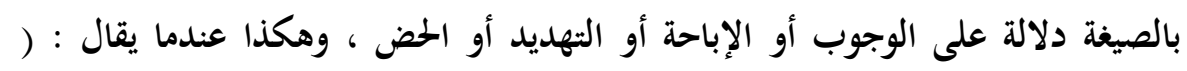

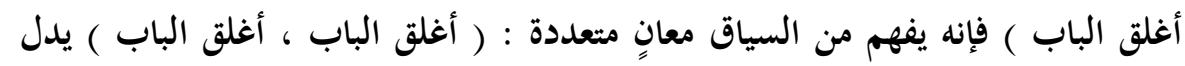

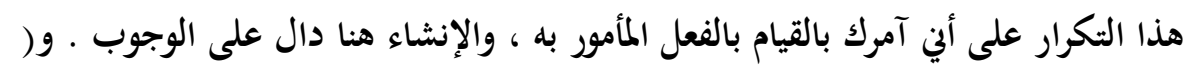

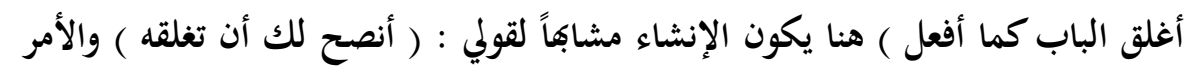

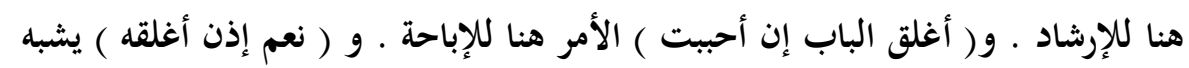

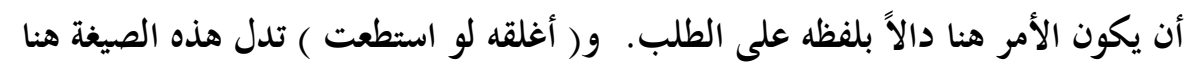


على الثهديد والوعيد . ويصح أيضاً أن نستعمل الأفعال المساعدة : ( يجيوز أن تغلقه )

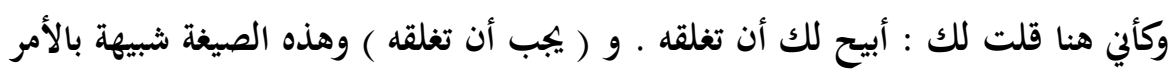

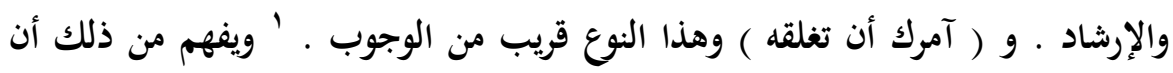

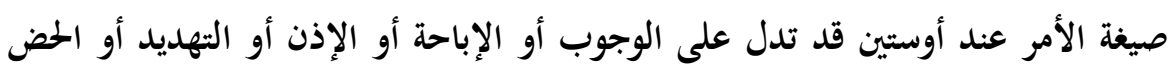

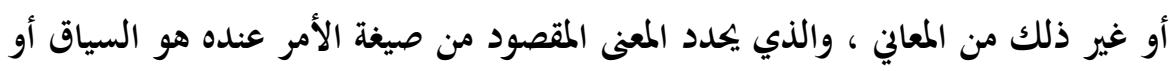

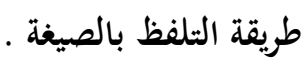

ونجد أن علماء اللغة المعاصرين قد تحدثوا عن أوجه الطلب حسب تحليل نظرية

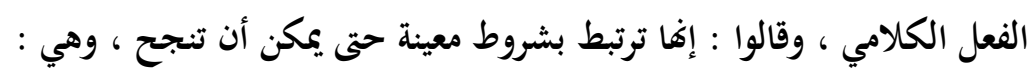
1- يجب على الطالب أن يكون له مطلب يمكن تحقيقه موضوعياً ، أي : أن يقدم أنيا

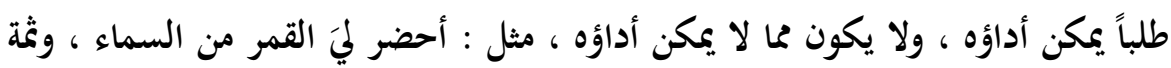

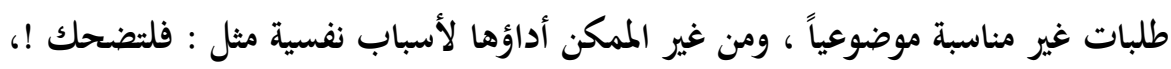

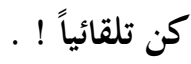

r- يجب أن يكون الطالب على اقتناع بأن المطلوب منه الطلب يمكنه أن يُبَبِّ ،

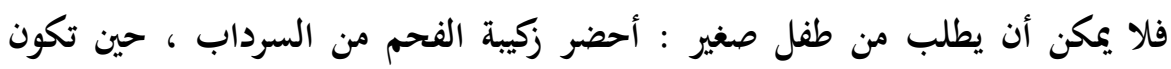
الزكيبة ثقيلة جداً .

r- يجب أن يكون الطالب على اقتناع بأن الطلب مقبول في حيط نفسي أو

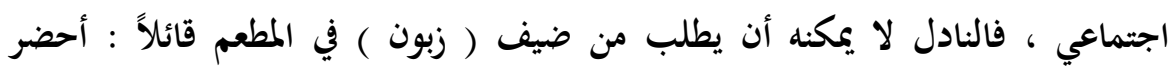

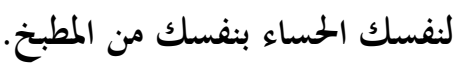

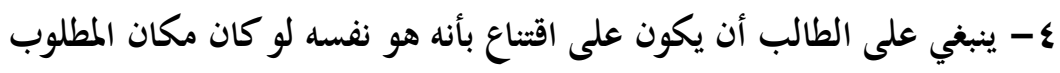

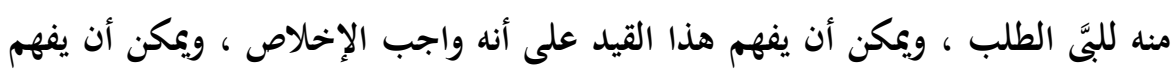

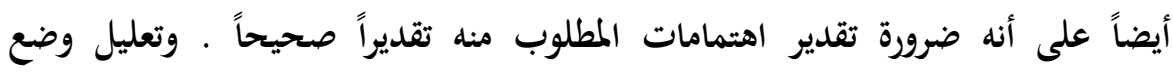

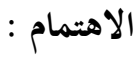


1- رجاء معلل : من فضلك امسح السبورة حتى يمكن أن نواصل الحساب . ץ- نصيحة معللة : حتى يمكنك أن تواصل الحساب أنصحك بأن تمسح السبورة

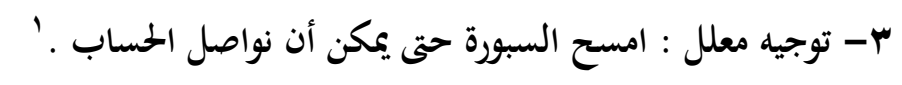
ع- إيعاز : ربما من غير المناسب أن تمسح السبورة الآن .

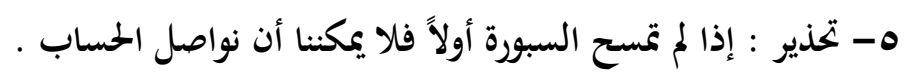

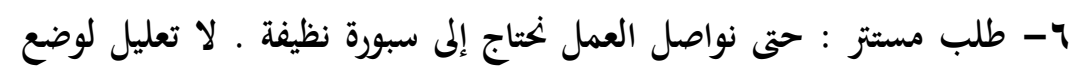

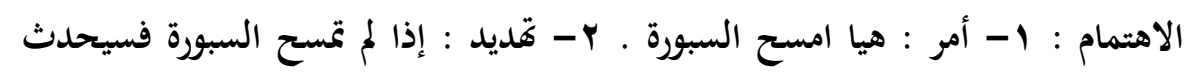

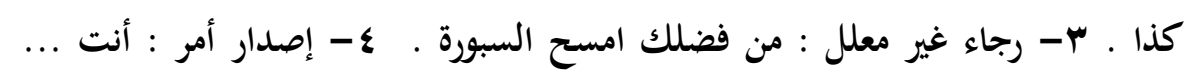

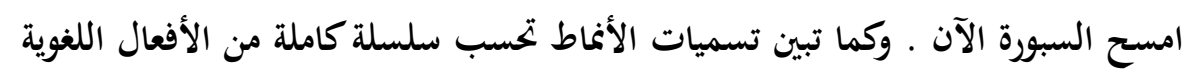

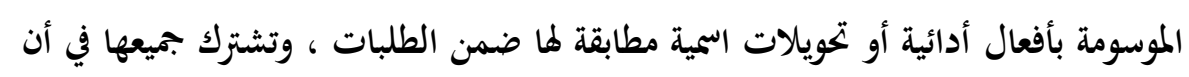

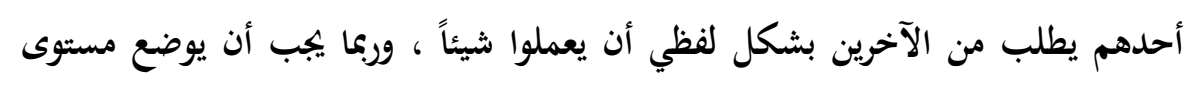

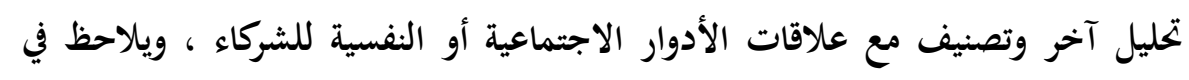

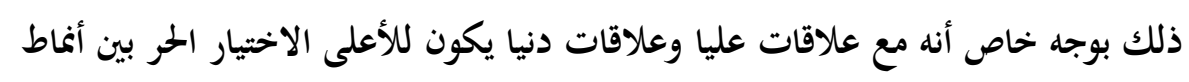

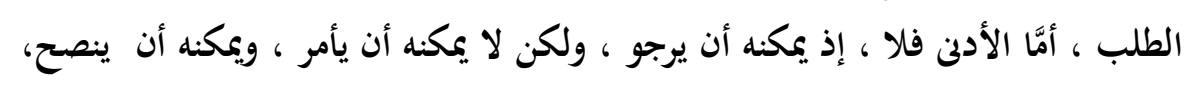

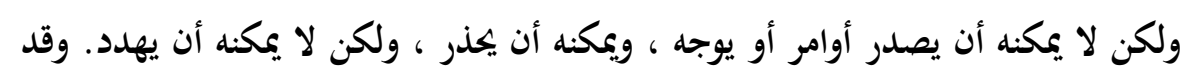

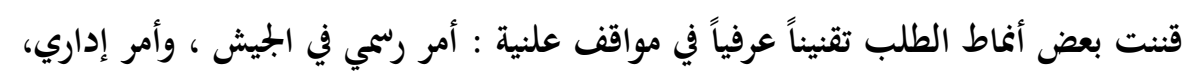

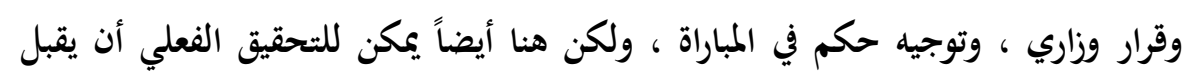

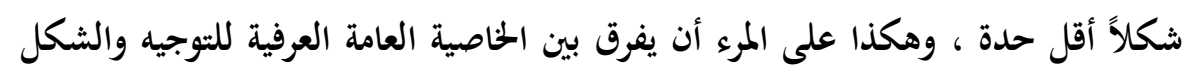

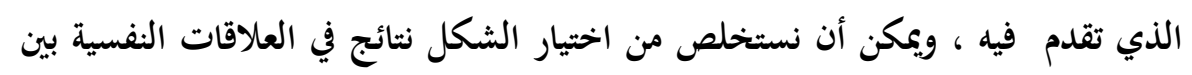

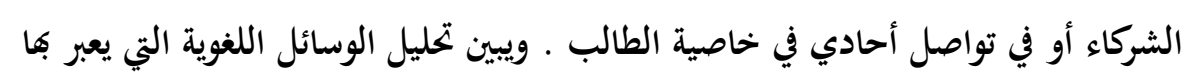
عن أوجه الطلب أنهالا تقدم أوجه الطلب صيغة جملة الطلب في صيغة ( فعل ) الأمر

' ) كارل - ديتربونتج في المدخل إلى علم اللغة - ترجمة وتعليق د/سعيد حسن بحيري : . بـr 
المنسوبة إلى الطلب في الأنحاء فقط ، بل تحديدات بسيطة أيضاً في صيغة الجمل الخبرية :

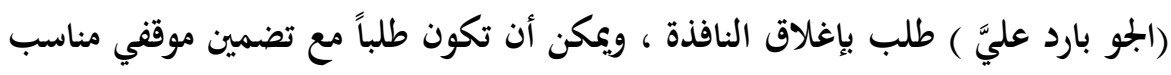

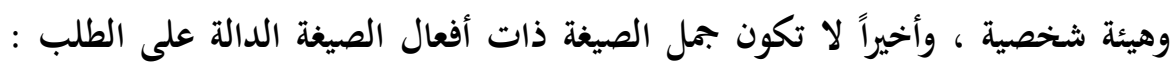

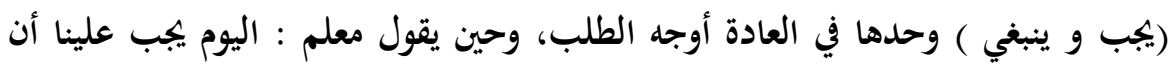

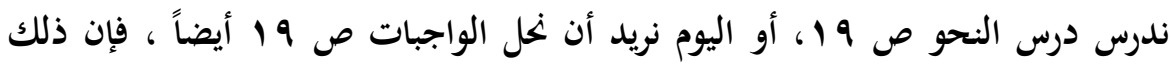

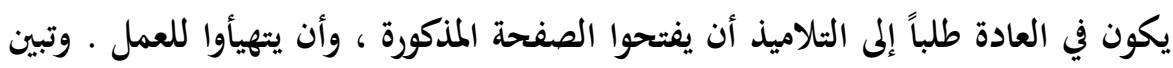
الأمثلة أنه توجد تراكيب نحوية نمطية للتعبير عن أفعال لغوية محددة ، وأن الفعل المنجز المهال حقيقة لا ينتج إلا من سياق موقفي ـ فالكلام شيء معين وليس تحقيقاً لنظام مقدم ، ويصير

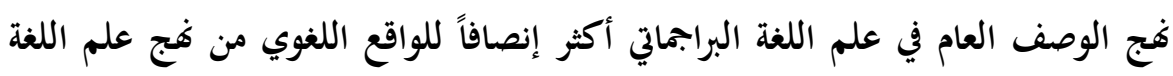

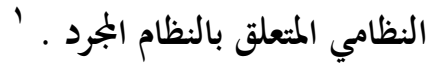

فقد تحدث علماء اللغة المعاصرون عن ارتباط أفعال الكلام بشروط معينة حتى

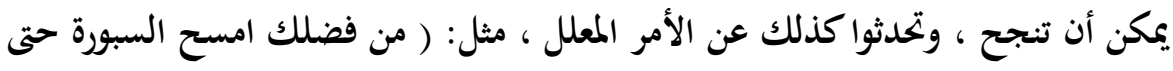

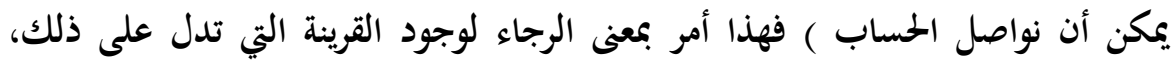

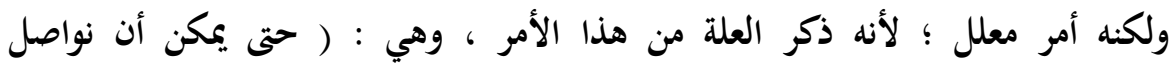

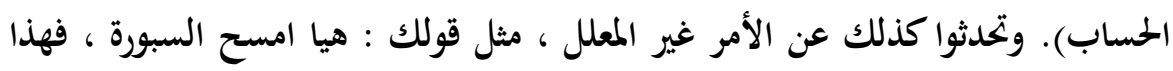

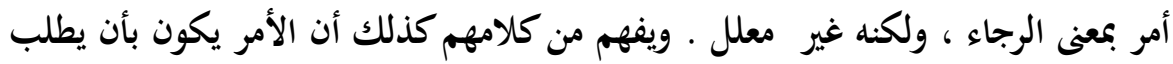

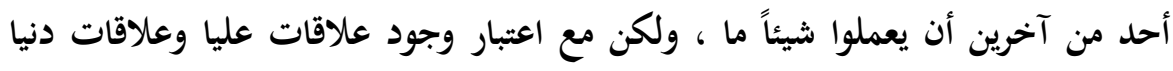

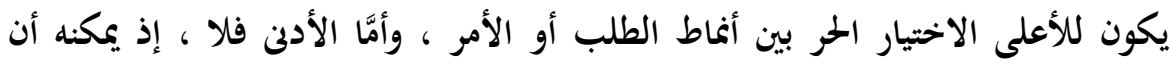

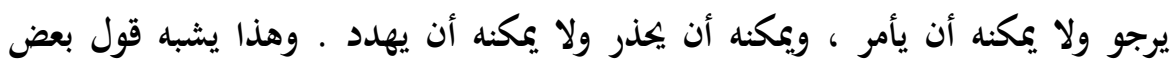
الأصوليين في تعريف الأمر : بأنه طلب الفعل على جهة الاستعلاء ، وقال آخرون من آند الأصوليين بعدم اشتراط الاستعلاء في الأمر ، وهو القول الراجح كما سبق أن بينت في

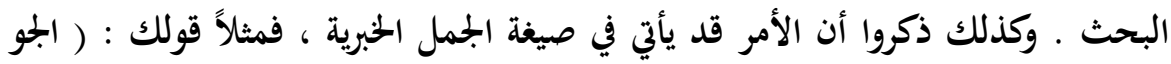

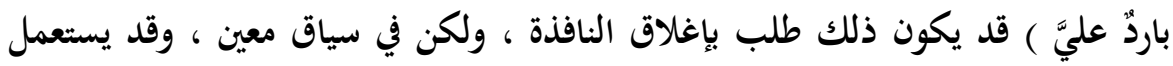


الفعل ( يجب أو ينبغي ) في الدلالة على الطلب ، فحين يقول معلم : اليوم يجب علينا أن

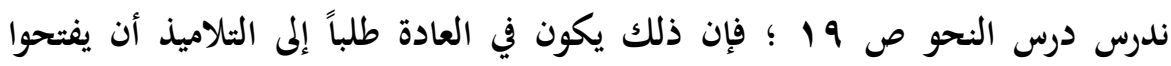
الصفحة المذكورة وأن يتهيأوا للدراسة . لـون

وقد تحدثت إيونا بلسيكا " Iwona plisiecka " عن أهمية السياق في

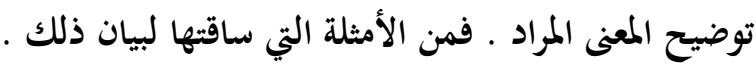

1-close the cover before striking( the match) .

أغلق علبة الكبريت قبل أن تشعل العود .

- give me tickets for two non students please

r أعطني تذكرتين لاثنين من غير الطلاب من فضلك .

3-No smoking

ممنوع التدخين . فعبارة : no smoking منوع التدخين ؛ لتوجيه المستمع أو القارئ إلى عدم التدخين في المنطقة الجماورة لموقع الكلام .

4- This road is slippery when wet .

$$
\text { هذا الطريق زلق عندما يكون مبللاً . }
$$

$$
\text { التوجيه غير المباشر ، (indirect directive ) }
$$

- drive carefully ( because this road is slippery owhen wet ).

قُُْْ السيارة بعناية لأن هذا الطريق زلق عندما يكون مبللاً . فعبارة ( زلق عندما

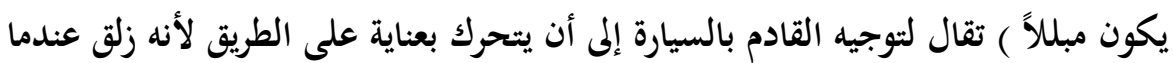

$$
\text { يكون مبلاًا. . }
$$

${ }^{1}$ (Iwona plisiecka: pragmatic perspectives on language and linguistics . volume 1 : speech actions in theory applied studies : 11 
6- two nonstudents, please.

اثنان من غير الطلاب من فضلك ـ و في الاستخدام الحريف ل ( please ) ما يدل على

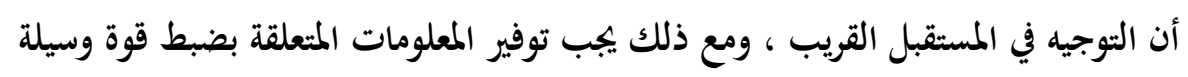

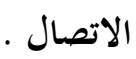

7- give/sell me tickets for two nonstudents ( L \& D directive ).

$$
\text { أعطني / بعُ لي تذكرتين لاثنين من غير الطلاب ( توجيه ) . }
$$

8- I would like tickets for two nonstudents ( $L \& D$ constative + indirect directive)

أود أن تعطين تذكرتين لاثنين من غير الطلاب ( التوجيه غير المباشر ) . directives توجيهات

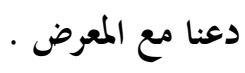

9- [Let,s get] on with the show !

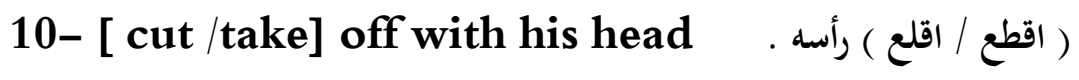
ويبدو أن جملة " [cut/take] off with his head] " قد توحي بأن البناء

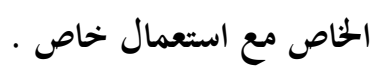

11- off with ( $3^{\text {rd }}$ person possessive ) NP' is used to direct the hearer to 
cut /take off ( $3^{\text {rd }}$ person possessive )NP.

ثلاثة أشخاص أحدهم يأمر الآخر بقطع رأس الثالث . '

12- [please give me] some whiskey . request

$$
\text { من فضلك أعطني بعض الويسكي . ( طلب مؤدب ) }
$$

13- [ Give me ] some whiskey . order

$$
\text { أعطني بعض الويسكي · ( أمر صريح ) }
$$

14- some whiskey [ falling, watch out ] . warning

$$
\text { بعض الويسكي يسقط ، احترس · ( تحذير ) }
$$

15- some whiskey [ or your life ] . threat

$$
\text { بعض الويسكي أو حياتك ـ ( تقديد ) }
$$

16- [ Get down ] on the floor . (command)

$$
\text { انزل على الأرض ـ ( أمر صريح بلا جدال ) }
$$

17- [ take me ] to segova . (request)

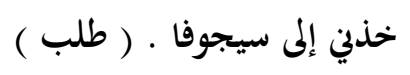

18- [ on the floor] Quickly . (command)

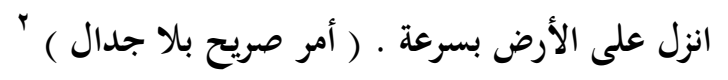

Iwona plisiecka: pragmatic perspectives on language and linguistics . ( ' volume 1 : speech actions in theory applied studies $: 13,14,15$

Iwona plisiecka: pragmatic perspectives on language and linguistics . ${ }^{\top}$ volume 1 : speech actions in theory applied studies :16 


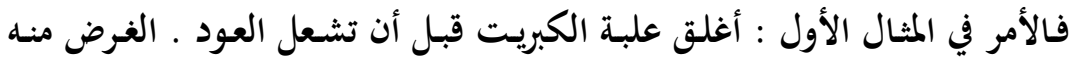

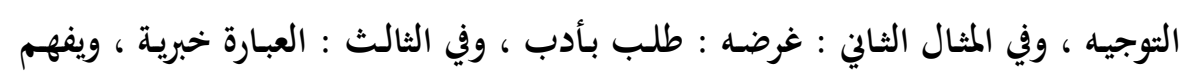

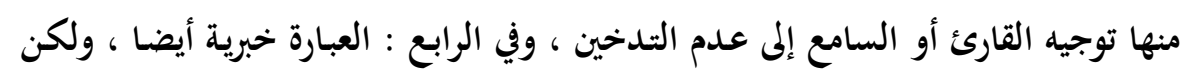

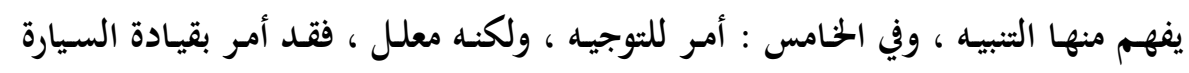

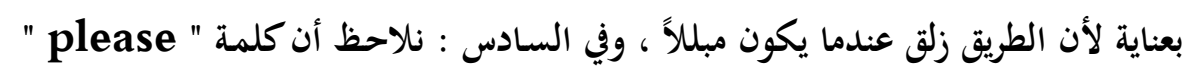

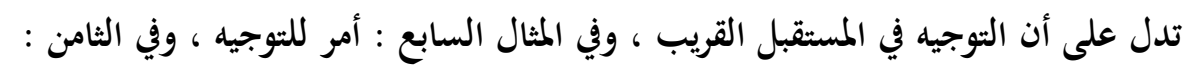

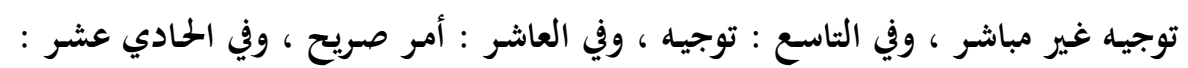

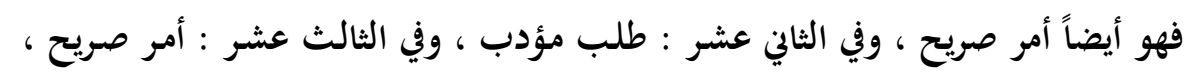

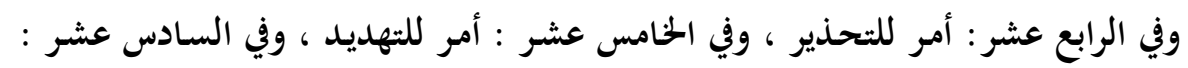

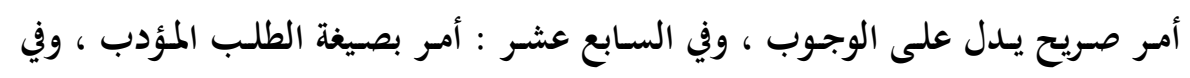

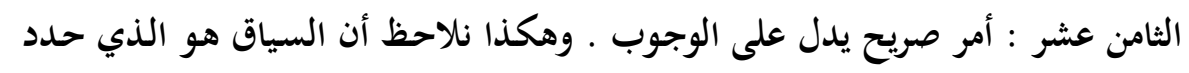

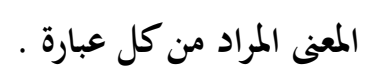

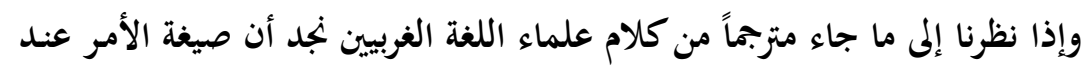

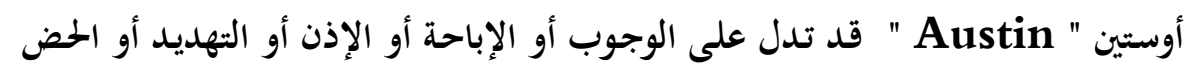

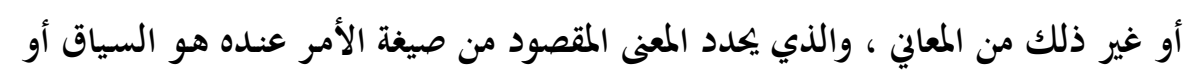

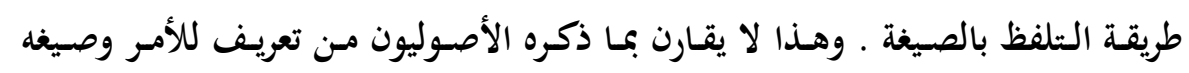

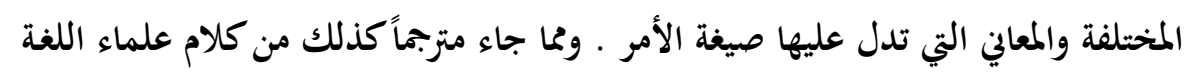

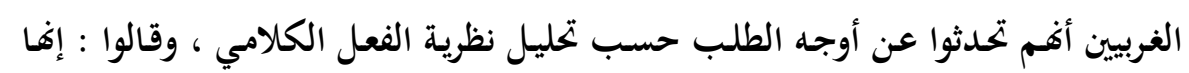

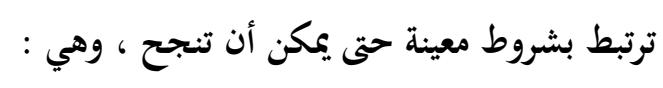
1- أن أن يكون الطلب مما يمكن أداؤه .

ب- يجب أن يكون الطالب على اقتناع بأن المطلوب منه الطلب يمكنه أن يُلبَّيّ .

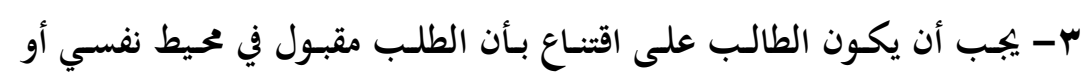

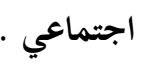


ع - ينبغي على الطالب أن يكون على اقتناع بأنه هو نفسه لو كان مكان المطلوب

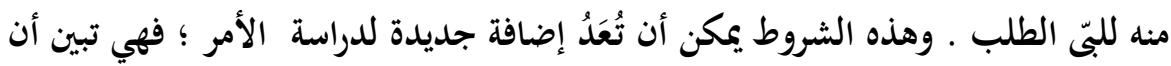
هذه الشروط تساعد على إيقاع الأمر وتنفيذه بالفعل .

وإذا نظرنا إلى أحدث ما كتبه علماء اللغة المعاصرون عن الأمر ، وذلك من خلال

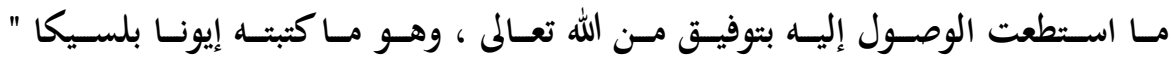
Iwona plisiecka ذكر ذلك في البحث ، فكلها تُعد دراسة يسيرة وبسيطة وغير متعمقة ، فهي لا تقارن

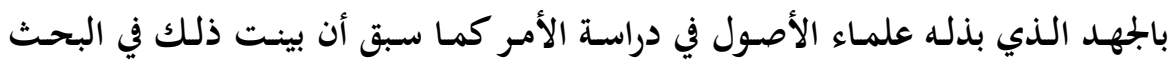

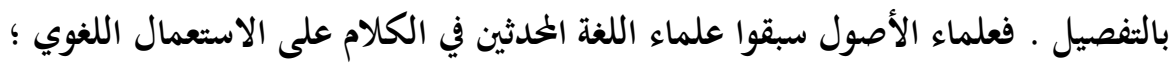
وذلك حين قسموا حقيقة الأسماء في اللغة إلى ثلاثة أقسام :

\section{1 - حقيقة لغوية وضعية .}

$$
\text { r - حقيقة عرفية بنوعيها ( خاصة وعامة ) . }
$$

ץ- حقيقة شرعية ـ وكذلك الثداولية كانت معروفة لدى علماء الأصول ، ولكنها

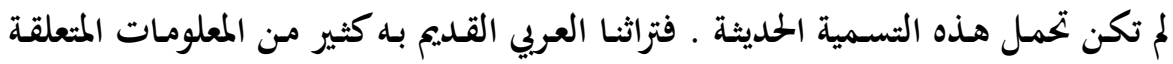

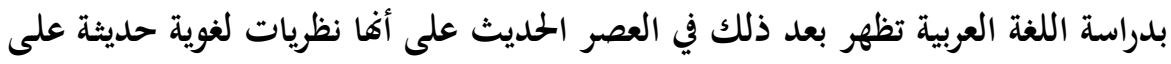

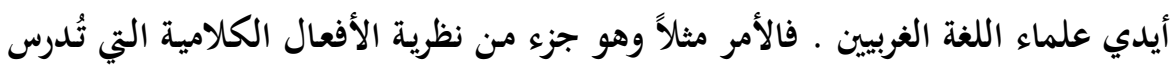
داخل دراسة لغوية حديثة تعرف باسم التداولية " pragmatics " فقد درسه علماء الأصول دراسة تفصيلية ودقيقة ومتعمقة تدل على عبقريتهم ، ومما يدل على ذلك تقدسيم

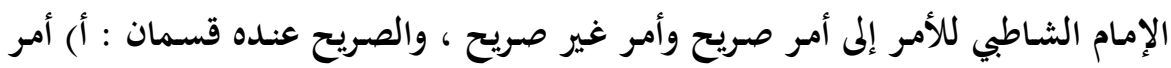

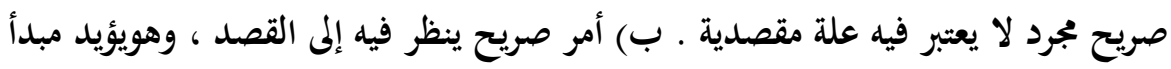

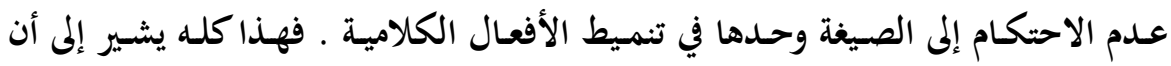

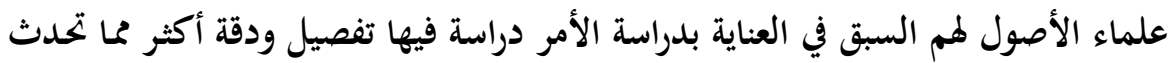

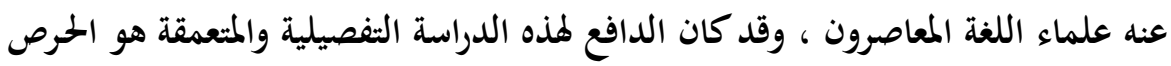

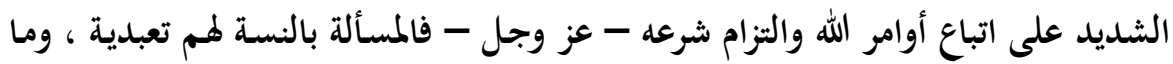




\section{rq}

بذله علماء الأصول من جهد في هذه الدراسة إلا بتوفيق من الله - عز وجل - وإلهام منه

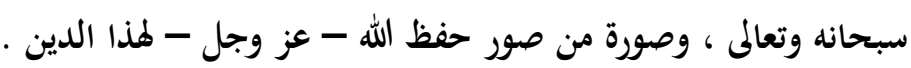


ا - إن تراثنا العربي قد كتبه علماء أجلاء حباهم الله بنعمة الذكاء والعبقرية ، فما ذكروه منذ مئات السنين بتفصيل دقيق ودراسة مستقيضة يذكره بعد ذلك علماء الغرب المعاصرون على أنه نظريات لغوية حديثة .

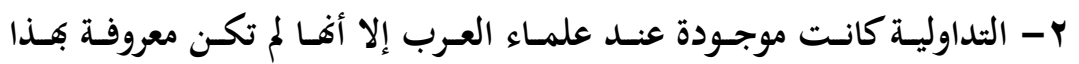

$$
\text { المصطلح الحديث . }
$$

بـ- إن علمـاء الأصـول قـاموا بدراسـة الأمـر دراسـة تفصسيلية مستفيضـة ودقيقـة

$$
\text { وتحدثوا عن أشياء }
$$

كثيرة في أثناء دراستهم للأمر لم يرد ذكرها عند علماء اللغة المعاصرين ، وهذا يدل على عبقرية علماء الأصول الذين خدموا اللغة العربية ، وأسهموا في إثراء تراثنا اللغوي . ع - يجب أن نخرص حرصاً شديداً على قراءة التراث اللغوي العربي والإلمام بكل ما فيه ؛ فإنه يكوي كنوزاً سطرها العلماء العرب منذ مئات السنين ، وفي العصر الحديث تجد سردي نظريات لغوية حديثة تبهر الكثيرين وعندما تطالعها ثم تعود لتقرأ التراث اللغوي العربي تجد ذلك مسطوراً فيه لكن دون أن يأخذ شكله الحديث كنظرية لغوية مستقلة ، وربما وجدات

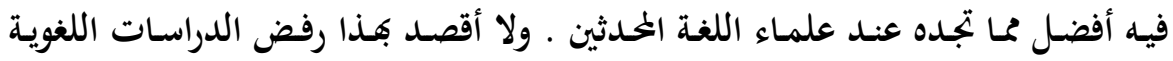
الحديثة ، ولكسن أقصد الاهتمام بالتراث اللغوي العربي القديم ففيه ما يكفي ويغني ، ولا مانع بعد ذلك من مطالعة الدراسات اللغوية الحديثة فقد تساعدنا في فهم ما لم نفهمه من تراثنا ، أو تكون عوناً لنا في محاولة لإعادة عرض تراثنا اللغوي بصورة أكثر إيضاحاً ويسراً ليسهل على المتعلمين فهمه ودراسته .

وفي فاية هذا البحث أسأل الله - عز وجل - أن يتقبل منّي هذا العمل المتواضع ،

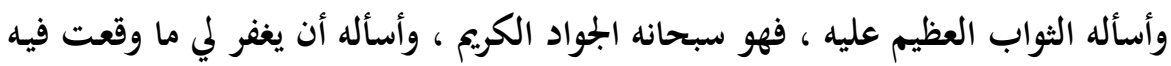

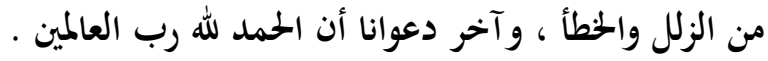




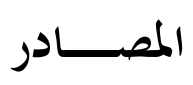

أولاً المصادر العربية :

* أمد بن حنبل ( أبوعبدالله أحمد بن محمد بن حنبل بن هلال بن أسد الشيباني ت

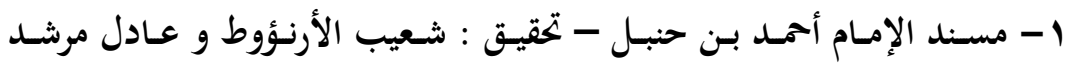

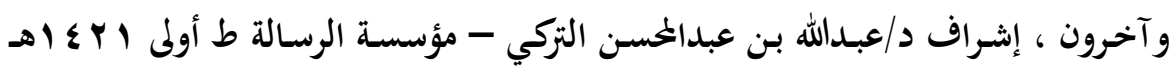

5r...

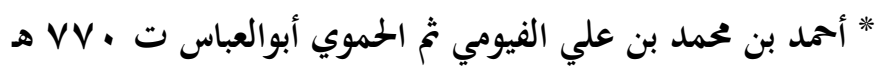

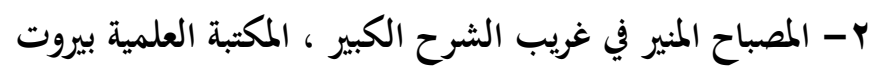

* الآمدي ( الإمام العلامة علي بن أبي علي محمد بن سالم التغلبي الآمدي ت

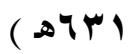

ب- الإحكام في أصسول الأحكام - علق عليه الشيخ عبدالرزاق عفيفي ، دار

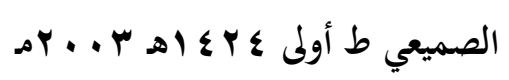

* امرؤ القيس ( امؤُ القيس بن حجر بن الحارث بن عمرو بن حجر ت . م ق .

ع - ديوان امرئ القيس - تحقيق محمد أبوالفضل إبراهيم - دار المعارف ط الرابعة

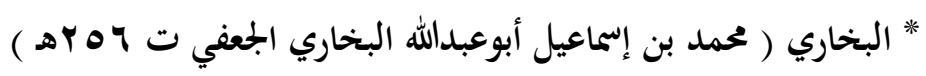

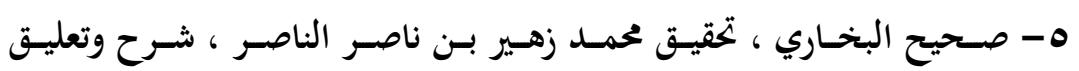

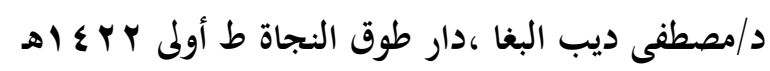

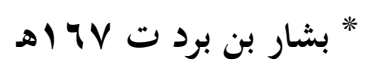


rr

צ- ديوان بشار بن برد ، شرح وتكميل أ/عمد الطاهر بن عاشور ، تعليق محمد رفعت فتح الله ومحمد شوقي أمين ، مطبعة لجنة التأليف والتزبمة والنشر القاهرة * البيهقي ( أحمد بن الحسين بن علي بن موسى الحسروجردي الحراساني أبوبكر

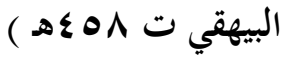

- V السنن الكبرى للبيهقي ، تحقيق محمد عبدالقادر عطا ، دار الكتب العلميـة

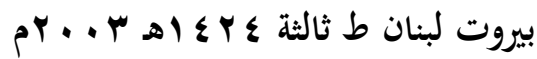

* الجحويني ( إمـام الحـرمين أبوالمعـالي عبداململك بـن عبـدالله بـن يوسف الجـويني ت

$(\infty \leq \vee \wedge$

^- البرهـان في أصـول الفقه ، حققه وقدمـه ووضع فهارسه د/عبدالعظيم محمود

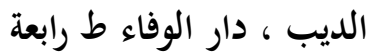

* الحساكم ( أبوعبدالله الحاكم محمد بـن عبدالله بـن محمدل بـن حمدويه بـن نعيم بـن

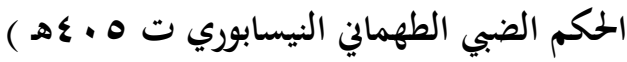

9- المستدرك على الصحيحين ، تحقيق مصطفى عبدالقادر عطا ، دار الكتب

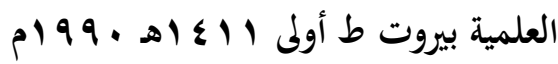

* الخضري ( الشيخ محمد الخضري ت 0 ؛ ب اهـ )

• 1- أصول الفقه ، دار الحديث

* السبكي ( علي بن عبدالكافي السبكي ت

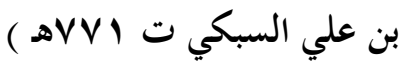

1 1 - الأبهاج في شرح المنهاج ، كتب هوامشه وصححه جماعة من العلماء بإشراف

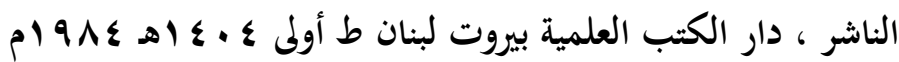

* السرخسي ( أبوبكر محمد بن أحمد بن أبي سهل السرخسي ت • 9 §هـ ) 
r r أ - أصول السرخسي ، حقق أصوله وعلق عليه د/رفيق العجم ، دار المعرفة

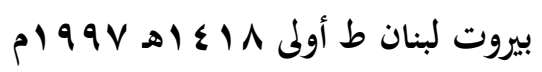

* الشاطبي ( إبراهيم بن موسى بن محمد اللخمي الغرناطي الشهير بالشاطبي ت

$$
\text { ( ov } 9 \text {. }
$$

با أ- الموافقات ، تحقيق أبي عبيدة مشهور بن حسن آل سلمان ، دار ابن عفان

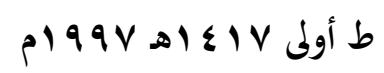

* الشنقيطي ( محمد الأمين بن محمد المخختار الشنقيطي ت به ب اهـ )

ع ا- نثر الورود على مراقي السعود - دار الدعوة للطبع والنشر

* الشيرازي ( إبراهيم بن علي بن يوسف الفيروزآبادي الشيرازي أبوإسحاق ت

$(\rightarrow \leq \vee 4$

1 1 - النبصرة في أصول الفقه ، تحقيق د/عمد حسن هيتو ، دار الفكر دمشق ط

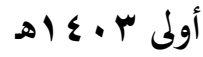

| (بدالكريم بن علي بن محمد النملة

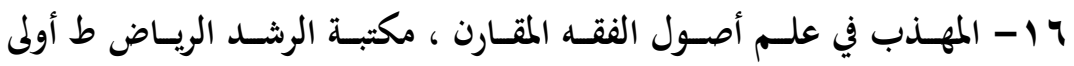

$$
\text { plq99 هis r. }
$$

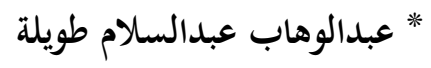

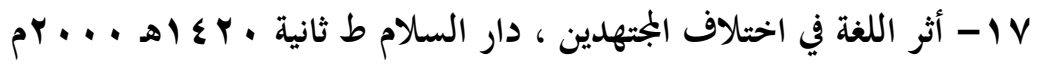

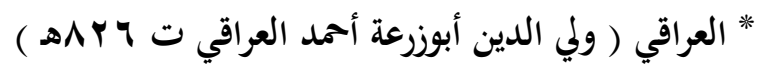

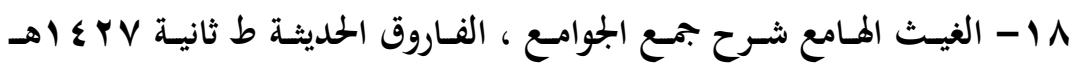

$$
\text { br...t }
$$

" علي بن محمد بن علي الزين الشريف الجرجاني ت 414 مهـ 
9 1 - كتـاب التعريفـات ، ضـبطه وصـححه جماعـة مـن العلمـاء بإشـراف الناشـر ،

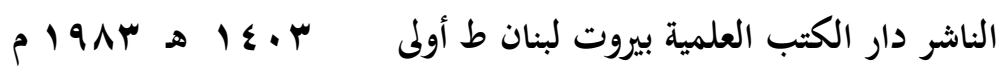
* الغزالي ( محمد بن محمد الغزالي أبوحامد ت ه ـ هـ )

• ץ- المستصفى في علم أصول الفقه ، تحقيق محمد عبدالسلام عبدالشـافي ، دار

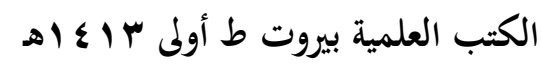

* القالي ( أبوعلي إسماعيل بن القاسم القالي البغدادي ت به بهـ )

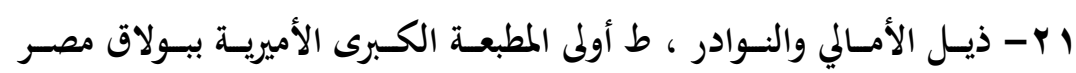

E

* محمد العبد

r r r - النص والخطـاب والاتصـال ، الأكاديميـة الحديثـة للكتـاب الجـامعي ط أولى

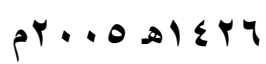

* محمد بن عبدالرحمن بن العباس بن عبدالرحمن بن زكريا البغدادي المخلِّصص ت

מTa

بr - المخلصسيات ، تحقيسق نبيـل سـعدالدين جـرار ، وزارة الأوقـاف والثــئون

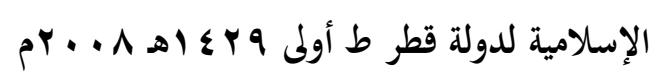

* محمد سليمان عبدالله الأشقر

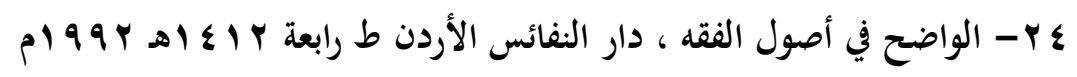

$$
\text { * }
$$

ه Y - آفاق جديدة في البحث اللغوي المعاصر ، دار المعرفة الجامعية

$$
\text { * م / مسعود صحراوي }
$$


ج ب- التداولية عند العلماء العرب ( دراسة تداولية لظاهرة الأفعال الكلامية في

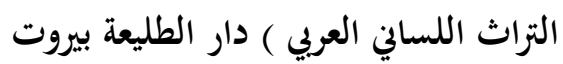
* مسلم ( مسلم بن الحجاج أبوالحسن القشيري النيسابوري ت ( آ بهـ ) V V - صـحيح مسـلم ، تحقيق محمـد فؤاد عبـدالباقي ، دار إحيـاء التراث العـبي بيروت

$$
\text { * م / مصطفى سعيد الحنن }
$$

^ץ- أثر الاختلاف في القواعد الأصسولية في اختلاف الفقهاء ، مؤسسة الرسالة

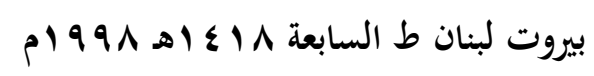

* ابن منظور ( محمد بن مكرم بن علي أبوالفضل جمال الدين بن منظور الأنصاري

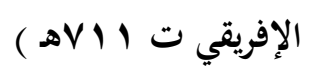

q ץ - لسان لعرب ، دار صادر بيروت ط ثالثة ـ إ اهـ

* أبويعلى ( أبويعلى أحمد بن علي بن المثنى بن يهيى بن عيسى بن هلال التميمي

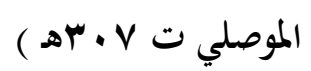

• ب- مسند أبي يعلى ، تحقيق حسين سليم أسد ، دار المأمون للتراث دمشق ط

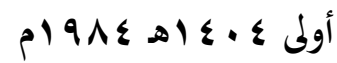

$$
\begin{aligned}
& \text { ثانياً المصادر المترجمة : } \\
& \text { * د سعيد حسن بحيري }
\end{aligned}
$$

ا اس- المدخل إلى علم اللغة ،تأليف كارل ديتربونتنج ،ترجمة وتعليق د/ سعيد حسن

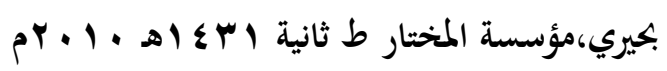

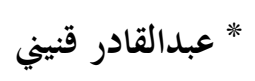


r r- نظرية أفعال الكلام العامة (كيف ننجز الأشياء بالكالام ) لأوستين ، ترجمة/

$$
\begin{aligned}
& \text { عبدالقادر قنيني ، إفريقيا الشرق | } 999 \\
& \text { مصادر أجنبية : }
\end{aligned}
$$

*Iwona witczak-Plisiecka

33- pragmatic perspectives on language and linguistics . volume 1: speech actions in theory applied studies . first publish ed 2010 